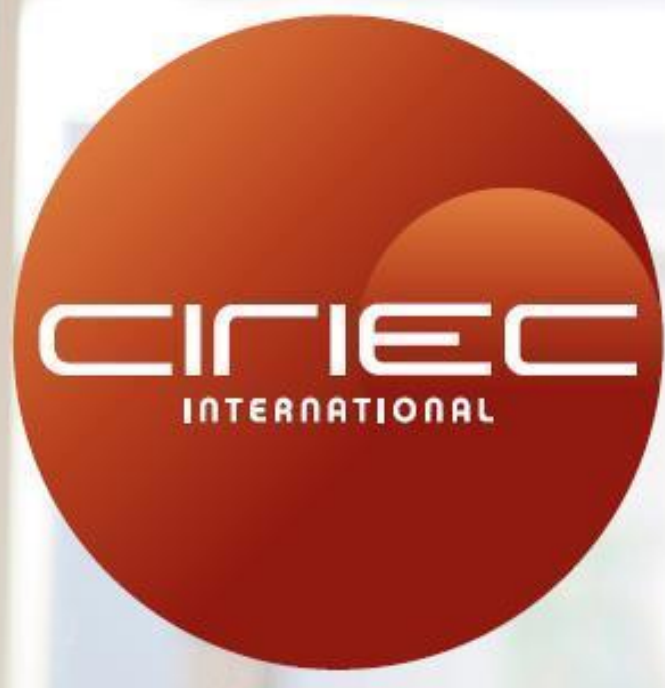

Working Paper

Falsas cooperativas de trabajadores y medidas adoptadas por los poderes públicos en España para combatirlas

Gemma FAJARDO GARCÍA

CIRIEC No. $2019 / 30$ 
CIRIEC activities, publications and researches are realised with the support of

Les activités, publications et recherches du CIRIEC sont réalisées avec le soutien de
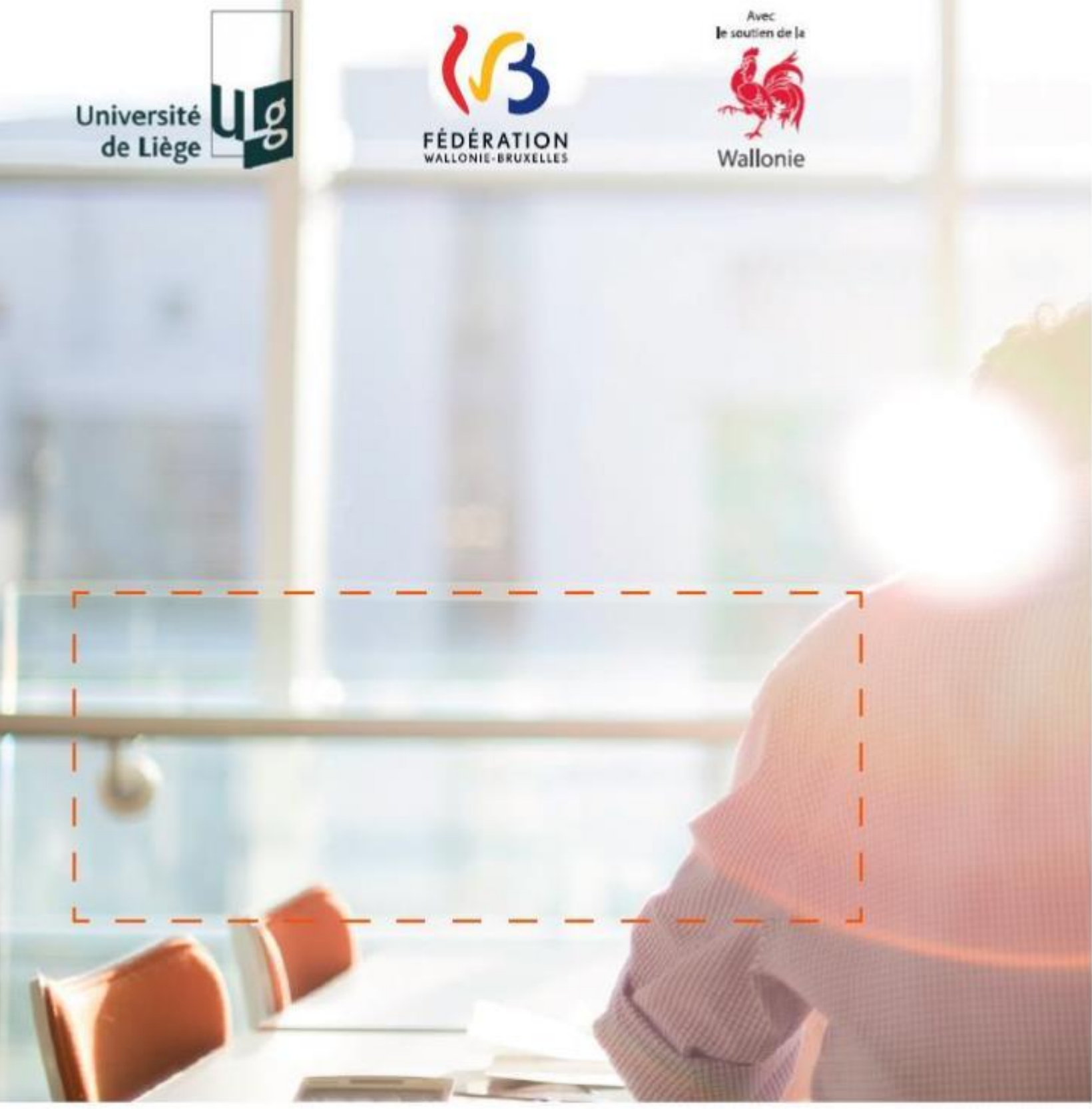


\title{
Falsas cooperativas de trabajadores y medidas adoptadas por los poderes públicos en España para combatirlas*
}

\author{
Gemma Fajardo García ${ }^{1}$
}

Este trabajo es resultado del Proyecto I+D+i: Economía Social, Autogestión y Empleo (DER2016-78732-R) financiado por el Ministerio de Ciencia, Innovación y Universidades, Agencia Estatal de Investigación y el Fondo Europeo de Desarrollo Regional (FEDER).

Working paper CIRIEC No. 2019/30

\footnotetext{
* Paper presented at the $7^{\text {th }}$ CIRIEC International Research Conference on Social Economy "Social and Solidarity Economy: Moving Towards a New Economic System", Bucharest (Romania), 6-9 June 2019.

${ }^{1}$ Profesora Titular Derecho Mercantil, Investigadora IUDESCOOP y CIRIEC (España) (Email: fajardo@uv.es).
} 


\section{Abstract \\ Fake Worker Cooperatives and Measures Adopted by the Public Authorities in Spain to Combat them}

Fake cooperatives are considered those entities that are constituted as cooperatives, but do not carry out a cooperative activity in accordance with the purposes and characteristics that are typical of cooperatives (autonomy, democratic management, economic responsibility, voluntary adhesion, ...). Fake cooperatives can occur in all cooperative models and in all sectors. The reasons in each case may be different: not taking risks, ensuring customers or saving costs are usually the most common. The main signal that warns of the existence of a fake cooperative is the lack of independence of the cooperative or its members. This dependence is appreciated by the presence of a series of indications and also the impossibility or difficulty that the members have to avoid this dependence. Indications of dependency are not enough, it is necessary to confirm such dependency, analyzing if the members mostly accept the situation or are forced to go through it without options for change.

In this paper we analyze the case of some fake cooperatives that have arisen to outsource the work, so that the workers, as members of the cooperative, assume the costs and risks of said activity. It is not only about avoiding the enforcement of labor law, normally there are other consequences associated, such as corporate responsibility derived from the activity carried out. These fraudulent actions occur in many places and are issues of global concern. Precisely, "Combating false cooperatives" is part of the Joint Action Plan agreed by ILO and ICA in 2018. But our objective in this paper is to analyze the latest cases of fake cooperatives that have been detected in Spain, in relationship with worker cooperatives. These cases have occurred in three areas: transport workers, slaughterhouse workers and intermittent workers in billing cooperatives.

This paper is structured in the following sections: 1. Exposure of the legal elements that condition the actions of the promoters of the fake cooperatives: characteristics of the cooperative, labor and social security legislation; 2 . Analysis of the organization and performance in the three models of fake work cooperatives that are the object of attention (transport, slaughterhouse and billing cooperatives); 3. Measures adopted by the public authorities to combat them: a) Measures adopted in cooperative legislation; b) Measures adopted from the inspection and control function of the Public Administration, in matters of cooperatives and employment; c) Judgments issued by the Supreme Court and other courts, and 4. Assessment of the measures adopted and other proposals.

Keywords: worker cooperatives; fake cooperatives; law fraud; labor rights; rights to social security; cooperative legislation; self-management

JEL Codes: J18; J54; K22; K31 


\section{Resumen}

Falsas cooperativas se consideran aquellas entidades que se constituyen como cooperativas, pero no llevan a cabo una actividad cooperativa de acuerdo con los fines y características típicas de las cooperativas (autonomía, gestión democrática, responsabilidad económica, adhesión voluntaria, ...). Las falsas cooperativas pueden darse en todos los modelos cooperativos y en todos los sectores. Las razones en cada caso pueden ser diferentes: no asumir riesgos, garantizar clientes o ahorrar costos, son generalmente los más comunes. La señal principal que advierte de la existencia de una falsa cooperativa es la falta de independencia de la cooperativa o de sus miembros. Esta dependencia es apreciada por la concurrencia de una serie de indicaciones y también por la imposibilidad o dificultad que tienen los miembros para evitar esta dependencia. No es suficiente que haya indicios de dependencia, es necesario confirmar, analizar si los miembros en su mayoría aceptan la situación o se ven obligados a pasar por ella sin opciones de cambio.

En este trabajo, hemos analizado el caso de algunas falsas cooperativas que han surgido para externalizar el trabajo, para que los trabajadores, como miembros de la cooperativa, asuman los costos y riesgos de dicha actividad. No se trata solo de evitar la aplicación de la legislación laboral, normalmente hay otras consecuencias asociadas, incluso más graves, como la responsabilidad derivada de la actividad realizada. Estas acciones fraudulentas ocurren en muchos lugares y son un tema de preocupación mundial. Precisamente, "Combatir las falsas cooperativas" es parte del Plan de Acción Conjunta acordado por la OIT y la ACl en 2018. Pero nuestro objetivo en esta ocasión es analizar los últimos casos de falsas cooperativas que se han detectado en España, en relación con cooperativas de trabajadores. Estos casos han ocurrido en tres áreas: trabajadores de transporte, trabajadores de mataderos y trabajadores intermitentes en cooperativas de facturación.

Este estudio se estructura en las siguientes secciones: 1. Exposición de los elementos legales que condicionan en estos casos las acciones de los promotores de falsas cooperativas: características de la legislación cooperativa, laboral y de seguridad social; 2. Análisis de la organización y funcionamiento en los tres modelos de cooperativas falsas de trabajo que son objeto de atención (cooperativas de facturación, del sector cárnico y de transportes); 3. Medidas adoptadas por las autoridades públicas para combatirlas: a) Medidas adoptadas en la legislación cooperativa; b) Medidas adoptadas desde la función de inspección y control de la Administración Pública, en materia de cooperativas y empleo; c) Sentencias emitidas por el Tribunal Supremo y otros tribunales, y 4 . Evaluación de las medidas adoptadas y otras propuestas.

Palabras clave: Cooperativas de trabajadores; Falsas cooperativas; Fraude de ley; Derechos laborales; Derecho a la Seguridad Social; Legislación cooperativa; Autogestión.

JEL Codes: J18; J54; K22; K31 


\section{Introducción}

Se denominan falsas cooperativas, aquellas empresas que constituidas formalmente como cooperativas no llevan a cabo una actividad cooperativizada conforme con los fines y características que son propios de éstas (autonomía, gestión democrática, responsabilidad económica, adhesión voluntaria, ...), sino que se han constituido, o son utilizadas, para otros fines. En ocasiones se busca no asumir riesgos, asegurar la clientela, ahorrarse gastos, evitar la aplicación de la ley o acceder a subvenciones y ayudas.

Falsas cooperativas pueden darse en todos los modelos de cooperativas y en todos los sectores y puede decirse que constituyen una preocupación a nivel global. Precisamente, "Combatir falsas cooperativas" forma parte del Plan de acción conjunto acordado por OIT y ACl en 2018.

Muchas veces, la principal señal que advierte de la existencia de una cooperativa falsa es su dependencia de otra entidad o persona; y esto llama la atención porque la independencia es un rasgo que debe estar presente siempre en la cooperativa y cuya importancia se destaca como uno de los principios que reflejan la identidad cooperativa.

En este trabajo vamos a analizar el caso de algunas falsas cooperativas creadas para acogerse al especial régimen jurídico de las cooperativas sin compartir sus fines, evitando así la aplicación de las normas que por razón de la actividad desarrollada por la cooperativa o por sus socios debería serle aplicable. En ocasiones se ha tratado de evitar la normativa aplicable a los trabajadores autónomos y en otras la normativa aplicable a los trabajadores dependientes.

Los casos que vamos a analizar son de cooperativas de trabajadores que se han considerado falsas en España en los últimos años. Vamos a ver sus características y la respuesta que desde las instituciones públicas se está dando ante este fenómeno. Como los casos se han dado en diversos sectores, con diversos modos operandi y diversas soluciones propuestas, vamos a analizar de forma separada los diversos supuestos, sin perjuicio de que podamos llegar a conclusiones finales comunes a todos ellos.

Los sectores en los que se han denunciado supuestos de falsas cooperativas recientemente han sido, en cooperativas de facturación, cooperativas cárnicas y cooperativas de transporte. 


\section{Conceptos y normas aplicables}

Para comprender los supuestos que van a analizarse conviene tener en cuenta qué se entiende en derecho español por cooperativa de trabajo asociado (CTA) y qué le diferencia de otras modalidades cooperativas próximas. En España la regulación jurídica de la cooperativa es competencia de las Comunidades Autónomas y en menor medida del Estado, por ello, en este trabajo las referencias a la legislación cooperativa van a hacerse principalmente a la ley estatal ${ }^{2}$ y a las leyes de las comunidades que cuentan con más cooperativas de trabajo asociado (Andalucía ${ }^{3}$, Cataluña ${ }^{4}$, Comunidad Valenciana ${ }^{5}$ y País Vasco ${ }^{6}$.

Las CTAs se definen en la ley estatal de cooperativas como "... las que tienen por objeto proporcionar a sus socios puestos de trabajo, mediante su esfuerzo personal y directo, a tiempo parcial o completo, a través de la organización en común de la producción de bienes o servicios para terceros" (art. 80.1 LCE).

La necesidad común que justifica la existencia de la cooperativa en el caso de las de trabajo asociado es la de conseguir un trabajo para sus socios en las mejores condiciones posibles, porque no van a querer menos los socios.

En cuanto al objeto social, esto es, la actividad que va a desarrollar la cooperativa para alcanzar tal fin, podrá consistir en cualquier actividad económica no prohibida por ley $^{7}$, que se desarrolle empresarialmente ${ }^{8}$ por medio del trabajo personal y directo de los socios. La LCE exige además que la producción de bienes o servicios sea organizada en común por los socios, lo que refleja la naturaleza autogestionaria de la cooperativa y la independencia que debe caracterizarla. Podríamos añadir al anterior concepto, aunque pueda

\footnotetext{
${ }^{2}$ Ley 27/1999, (LCE., en lo sucesivo).

${ }^{3}$ Ley de Cooperativas de 2011 (LCA., en lo sucesivo).

${ }^{4}$ Ley de 2015 (LCC., en lo sucesivo).

${ }^{5}$ RD Legislativo de 2015 (LCCV., en lo sucesivo).

${ }^{6}$ Ley de 1993 (LCPV., en lo sucesivo). También tomaremos en cuenta la recién aprobada Ley de Cooperativas de Euskadi 11/2019, de 20 de diciembre (LC. Euskadi), aunque no entrará en vigor hasta finales de enero de 2020 (Disposición final 5a).

${ }^{7}$ Como dice la ley "Cualquier actividad económica lícita podrá ser organizada y desarrollada mediante una sociedad constituida al amparo de la presente ley" (art. 1.2 LCE).

${ }^{8}$ Como dice la ley en otro momento, la cooperativa se constituye para la realización de "actividades empresariales" encaminadas a satisfacer las necesidades y aspiraciones económicas y sociales de sus socios (art. 1.1 LCE); en este caso la necesidad o aspiración de tener un trabajo digno.
} 
parecer redundante, que la actividad cooperativa va a desarrollarse con el trabajo asociado de los socios ${ }^{9}$. Ello permite distinguir la cooperativa de trabajo asociado de otras cooperativas en las que los socios trabajan autónomamente aunque compartan bienes o servicios, lo que en derecho español se conoce como cooperativa de servicios o de servicios empresariales o profesionales.

En la práctica, los trabajadores que pretendan constituir una cooperativa tendrán que determinar en los estatutos si la finalidad, organización y funcionamiento de la cooperativa proyectada es más afín a una cooperativa de trabajo asociado, o a una cooperativa de servicios.

Si el objeto es poner en común su trabajo para desarrollar una actividad económica en nombre de la cooperativa, deberían constituir una CTA, ello implicará que la gestión de la actividad se llevará por los socios elegidos para ocupar los órganos de la cooperativa; los medios de producción necesarios serán de la cooperativa o estarán a su disposición; las relaciones con terceros se harán a través de la cooperativa; la cooperativa facturará, cobrará a los clientes, pagará los gastos y retribuirá a los socios en proporción a la contribución de cada uno en los resultados del ejercicio. El socio tendrá la condición de socio trabajador y de aportante de capital, sin perjuicio de que pueda tener otras relaciones con la cooperativa por el arrendamiento o cesión de bienes o derechos a la misma.

Si los trabajadores quieren en cambio desarrollar la actividad económica en nombre propio, conforme a su criterio, con sus clientes y sus propios medios, deberían constituir una cooperativa de servicios. En estos casos la cooperativa puede proporcionar las ventajas de una central de compra, una marca y modelo de gestión, y otros bienes y derechos comunes; incluso oportunidades de trabajo a realizar de forma autónoma o en colaboración con otros socios de la cooperativa. La cooperativa de servicios se caracteriza según la ley por asociar a personas titulares de explotaciones industriales o de servicios y a profesionales o artistas, que ejercen su actividad "en nombre propio". La cooperativa tiene por objeto prestar suministros o servicios a sus socios, también puede producir bienes para sus socios o realizar cualquier actividad encaminada a mejorar la actividad de sus socios (art. 98.2 LCE).

No siempre en la práctica están perfectamente delimitadas las cooperativas de trabajo asociado y las cooperativas de servicios, e igualmente,

\footnotetext{
${ }^{9}$ Como decía la anterior Ley estatal de cooperativas (LGC 1987) y destacan actualmente otras leyes cooperativas: los socios en la CTA "aportan", "ponen en común" su trabajo, o "producen en común" (art. 118.1 LGC; art. 89.1 LCCV; art 84.1 LCA, y art. 99.1 LCPV).
} 
con el transcurso del tiempo una cooperativa que inicialmente se planteó como de trabajo asociado puede evolucionar hacia una cooperativa de servicios y viceversa.

El marco jurídico aplicable tanto a las anteriores cooperativas como a sus socios es bastante diferente. En las CTA la condición de empresario es de la cooperativa, y sus socios, que han de ser personas físicas, tienen la condición de socios trabajadores. En las cooperativas de servicios sus socios tienen la condición de empresarios o de profesionales, y pueden ser tanto personas físicas como jurídicas. En estos casos la cooperativa desarrolla una actividad auxiliar a la de sus socios, les presta servicios que contribuyan a mejorar sus respectivas actividades, aquellas desarrolladas por los socios por cuenta propia. En cambio, en ambas cooperativas la relación que vincula al socio con la cooperativa es "societaria" o "cooperativa", no es laboral ni mercantil, es decir, se rige por los acuerdos adoptados por los socios y reflejados en los estatutos, reglamentos y libros de actas de la asamblea general.

Desde el punto de vista de las políticas públicas, las cooperativas de trabajo asociado son destinatarias de la mayor parte de las ayudas a la economía social y al cooperativismo, mientras que las de servicios no gozan de tal protección. Así mismo, desde el punto de visto fiscal, las cooperativas de trabajo asociado pueden ser calificadas como "especialmente protegidas" si cumplen ciertos presupuestos, lo que implica un mejor trato fiscal; mientras que las cooperativas de servicios no pueden acceder a esa condición.

Por último, desde el punto de vista de las obligaciones sociales de ambos tipos de socios, los socios trabajadores de una CTA pueden elegir estatutariamente su afiliación al Régimen General de la Seguridad Social (RGSS en lo sucesivo) o al Régimen Especial del Trabajador Autónomo (RETA en lo sucesivo), mientras que los autónomos sólo pueden estar afiliados al RETA. En el RGSS es el empresario el que tiene la obligación de cotizar a la Seguridad Social (SS), mientras que en el RETA es una obligación del socio ${ }^{10}$. Las coberturas en el RGSS son más completas que en el RETA y por tanto su coste también es mayor, pero por el contrario, la contribución al RETA es permanente mientras que en el RGSS el empresario puede cotizar por los días trabajados cuando el trabajador no tienen un contrato indefinido. Debe

\footnotetext{
${ }^{10}$ Ello no obstante, es habitual que sea la cooperativa la que haga frente al pago de la cuota, por cuenta de sus socios trabajadores. En estos casos, la LC. Euskadi exige que este compromiso conste en los estatutos y que las cuantías abonadas no se computen como parte del anticipo que se abona mensualmente al socio, sino como un gasto deducible para la determinación del excedente neto (art. 103.8).
} 
aclararse también en este punto que en derecho español, la vinculación del socio trabajador con la cooperativa puede ser a tiempo completo o parcial; y puede ser una vinculación de duración indefinida mientras no cause baja el socio o sea excluido de la cooperativa, o puede ser una vinculación de duración determinada. Los socios con vinculación de duración determinada no pueden superar la quinta parte del número de socios con vinculación indefinida (art. 13.6 LCE).

Las anteriores características y sobre todo el diferente marco jurídico aplicable a los socios trabajadores (trabajo asociado) y a los socios profesionales (trabajo autónomo) son la causa de muchas de las situaciones anómalas que se plantean en la práctica y que vamos a analizar a continuación.

\section{Las cooperativas de facturación}

Las llamadas coloquialmente cooperativas de facturación son cooperativas que se han constituido como de trabajo asociado, que han optado en sus estatutos sociales por acogerse al RGSS, y cuyos socios prestan servicios a terceros, normalmente con carácter eventual.

Se trata de empresas que ofrecen a sus socios una serie de servicios de gestión y de intermediación como sería propio de una cooperativa de servicios: contratación, facturación, alta y baja en la Seguridad Social, asesoramiento jurídico y fiscal, etc. Pero la actividad profesional no se realiza en nombre del socio por cuya cuenta actúa la cooperativa, sino en nombre de ésta, cobrando por ello una comisión que se descuenta cuando se le liquida al socio la diferencia entre los ingresos obtenidos del cobro de las facturas y los gastos que se le imputan.

La formalización de la cooperativa como de trabajo asociado permite al socio, no sólo facturar sin ser autónomo como anuncian estas empresas, sino acogerse al RGSS como trabajador a tiempo parcial, lo que le permite cotizar a la Seguridad Social sólo por los días que declare trabajados ${ }^{11}$, lo que no sería posible si cotizase como trabajador autónomo en el RETA. Este modelo de empresa se constituye como CTA para aprovecharse de su régimen jurídico, pero no es una CTA porque no hay trabajo asociado ni la necesaria actividad cooperativa generadora del puesto de trabajo para sus socios. Por ello se dice

\footnotetext{
${ }^{11}$ Art. 246 Texto Refundido de la Ley General de la Seguridad Social (RD. Legislativo 8/2015, de 30 de octubre).
} 
que es una falsa cooperativa, creada para huir del régimen aplicable al trabajo autónomo ${ }^{12}$.

Esta práctica, ha sido combatida como fraudulenta por la Inspección de trabajo y la Administración pública. Así, tras una actuación de la Inspección de Trabajo y Seguridad Social de Valencia en la Cooperativa Fidelis Factu (Factoo), se emitió un Informe recomendando la descalificación de la cooperativa porque "es una empresa instrumental, cuya actividad ilícita- desde la vertiente de la relación jurídica de seguridad social se concreta en la simulación de relaciones de trabajo dependiente (bajo la forma de socios-trabajadores) con la finalidad de tramitar periodos de alta en el Régimen General de la Seguridad Social de trabajadores que, en realidad, son trabajadores por cuenta propia, posibilitando así el incumplimiento por parte de estos "socios trabajadores" de las obligaciones de alta y cotización al Régimen Especial de Trabajadores Autónomos" (RETA). El Ministerio de Empleo y Seguridad Social acordó descalificar la Cooperativa en agosto de 2017 por hacer un uso irregular de la CTA, que podría considerarse fraude. Entre las conductas infractoras se cita: simular socios donde sólo hay trabajadores por cuenta propia, o la inexistencia de actividad cooperativizada. Esta resolución está recurrida judicialmente, y mientras tanto, Factoo se ha declarado voluntariamente en concurso de acreedores a la par que está redirigiendo a su clientela (potenciales socios) hacia otras nuevas cooperativas "hermanas" constituidas en Andalucía ${ }^{13}$.

Y es que la Comunidad Autónoma de Andalucía parece haber dado cobertura en su ley de cooperativas a este modelo, bajo el nombre de Cooperativa de Impulso Empresarial $(\mathrm{CIE})^{14}$. La CIE se califica como una "cooperativa de trabajo de régimen especial" y se define en la Ley como aquella que tiene por objeto: prestar determinados servicios comunes a las personas socias que les proporcione un ámbito donde desempeñar regularmente su actividad profesional, y/o realizar tareas de intermediación entre estos y las terceras personas a las que prestan sus servicios (art. 93.1 LCA y art. 81.1 RLCA). Las CIE suelen tener dos tipos de socios, los socios de

\footnotetext{
12 LOPEZ GANDÍA, 2017.

${ }^{13}$ Desde Junio de 2019 Factoo ha creado un Blog a través del cual recomienda a quienes quieren trabajar como autónomos (freelance) pero acogidos al RGSS, adherirse a nuevas cooperativas de trabajo asociado y cooperativas de trabajo de impulso empresarial, bajo la cobertura de la Ley andaluza de cooperativas (véase en: https://factoo.es/blog/factoo-tubuscador-de-cooperativas).

${ }^{14}$ También las leyes de cooperativas de Cantabria, Cataluña, Extremadura y Euskadi prevén este modelo de cooperativa, que aunque de momento no ha sido desarrollado su régimen jurídico, podrían seguir los pasos de la ley andaluza.
} 
estructura y los socios usuarios. Los primeros son quienes prestan los servicios, suelen ser personas jurídicas, su vinculación con la cooperativa es estable y tienen el control de la misma (aunque no pueden superar el $51 \%$ de los votos en la asamblea). Los socios usuarios son la gran mayoría de los socios, son quienes reciben los servicios a cambio de una contraprestación, son personas físicas y normalmente su vinculación es esporádica. Como dijimos al inicio, un rasgo que suele caracterizar a las falsas cooperativas es su falta de independencia, en este caso el régimen de dependencia se establece en el interior de la cooperativa. Para ello se establecen dos tipos de socios y se atribuyen derechos de voto para cada colectivo con independencia del número de personas que integren cada uno, ello permite que el colectivo con menos socios pueda tener más votos que el colectivo más numeroso.

Las irregularidades advertidas en este tipo de cooperativas son principalmente dos. Por una parte, el dar de alta a los socios usuarios en el RGSS en lugar del RETA tratándose de socios que desarrollan su actividad por cuenta propia. Esta irregularidad también ha puesto de manifiesto la inadecuación del RETA para aquellos autónomos que sólo consiguen trabajos esporádicos que no les permite pagar mensualmente el coste de la Seguridad Social. La segunda irregularidad deriva de la dualidad de socios que permite generar una relación de dependencia de unos frente a otros. Esta irregularidad se complementa con la confusión que se genera al calificar esta cooperativa como de trabajo, cuando el control de la misma no está en manos de trabajadores sino de personas jurídicas mercantiles, cuyos trabajadores son quienes prestan los servicios a los socios usuarios ${ }^{15}$.

\section{Las cooperativas en el sector cárnico}

En el sector cárnico se ha desarrollado en los últimos años un tipo de cooperativa cuya legalidad también es objeto de discusión. Se trata de CTAs cuyos socios trabajadores prestan sus servicios en las instalaciones de otras empresas, a través de la firma de un contrato de prestación de servicios entre la cooperativa y la empresa cesionaria de los mismos.

\footnotetext{
${ }^{15}$ Este modelo de cooperativa, con distintos tipos de socios, donde unos prestan servicios a otros, también se encuentra en las llamadas Cooperativas de Emprendedores, creadas en Navarra (CEN) y Asturias (ACELERA) para promover el emprendimiento. Unos socios son personas jurídicas, su voto es proporcional al capital aportado y pueden tener hasta el $49 \%$ de los derechos de voto; los otros son los profesionales que asesoran y los usuarios de los servicios. Estos últimos se conciben como socios colaboradores (no cooperadores) por lo que, aunque suelen ser la mayoría, sus derechos políticos y económicos en la cooperativa están limitados. Más ampliamente en FAJARDO y ALZOLA (2018).
} 
En los casos que se han dado a conocer a través de las resoluciones judiciales, la cooperativa no desarrolla una actividad económica propia más allá de ceder el trabajo de sus socios a otras empresas, y se trata de cooperativas que tienen miles de trabajadores asociados.

Se da también la circunstancia de que estas cooperativas, en sus estatutos, han optado por el RETA, y por lo general los socios de la cooperativa prestan sus servicios en condiciones menos favorables que los trabajadores de las empresas cesionarias.

La cuestión que se plantea es por tanto, si la cooperativa puede tener como actividad económica principal o única la cesión del trabajo de sus socios y en su caso, en qué condiciones debería hacerlo.

Para responder a esta pregunta deben tenerse en cuenta algunos preceptos de nuestro ordenamiento que son de aplicación en la materia, como el art. 43 del Estatuto de los Trabajadores (ET).

Según el primer párrafo de dicho precepto: la contratación de trabajadores para cederlos temporalmente a otra empresa solo puede realizarse a través de empresas de trabajo temporal (ETT) autorizadas. Una ETT se define como aquella cuya actividad fundamental consiste en poner a disposición de otra empresa usuaria, con carácter temporal, trabajadores por ella contratados ${ }^{16}$. Podría discutirse si una CTA podría ser una ETT en relación con sus socios trabajadores, pues no los contrata propiamente. La Ley que regula la ETT admite que cualquier persona física o jurídica podría obtener la autorización administrativa como ETT si cumple con los requisitos que la propia ley exige (disponer de estructura organizativa suficiente; dedicación en exclusiva; estar al corriente en sus obligaciones tributarias y con la seguridad social, constituir garantía financiera; no haber sido sancionada previamente e incluir en su denominación las siglas ETT). Esta Ley no sólo no excluye que una CTA pueda ser una empresa de trabajo temporal, sino que lo contempla expresamente, entendiendo que los trabajadores cuya actividad consista en prestar servicios en empresas usuarias puedan ser sus socios trabajadores (DA Tercera LETT). Esta norma establece además dos importantes excepciones tanto al régimen general de las CTA como de las ETT. En el primer caso, admitiendo que la CTA que desarrolle su actividad como ETT pueda tener un

\footnotetext{
${ }^{16}$ Art. 1.1 Ley 14/1994, de 1 de junio, por la que se regulan las empresas de trabajo temporal (LETT).
} 
porcentaje mayor de asalariados del que se le permite a cualquier $\mathrm{CTA}^{17}$. En el segundo caso, admitiendo que "Las relaciones entre la cooperativa que actúe como empresa de trabajo temporal y sus socios trabajadores o socios de trabajo cuya actividad consista en prestar servicios en empresas usuarias, así como las correspondientes obligaciones de Seguridad Social, se regirán por lo previsto en la legislación aplicable a dicho tipo de sociedades". Esta exclusión implica que los socios trabajadores de las cooperativas no cuentan con las garantías que la ley establece en favor de los trabajadores cedidos y que trata de evitar que los trabajadores cedidos tengan peores condiciones que los trabajadores contratados directamente por la empresa cesionaria ${ }^{18}$.

Según el párrafo segundo del art. 43 ET: se incurre en cesión ilegal de trabajadores cuando el objeto de los contratos de servicios entre las empresas se limite a una mera puesta a disposición de los trabajadores de la empresa; la empresa cedente carezca de una actividad o de una organización propia y estable; no cuente con los medios necesarios para el desarrollo de su actividad, o no ejerza las funciones inherentes a su condición de empresario. Las empresas (cedentes y cesionarias) que infrinjan esta norma responderán solidariamente de las obligaciones contraídas con los trabajadores y con la

${ }^{17}$ La DA Tercera señala que la CTA podrá contratar cuantos trabajadores precise para ponerlos a disposición de las empresas usuarias, aunque el número de asalariados con contrato por tiempo indefinido supere el $10 \%$ del total de sus socios. Hay que tener en cuenta que la ley estatal de cooperativas vigente al aprobarse la LETT era la LGC de 1987 en cuyo art. 118.7 se limitaba el número máximo de trabajadores asalariados que podía contratar una CTA al 10\% del número total de sus socios trabajadores. Ese límite se modificó en la actual LCE de 1999 que lo fija en el 30\% del total de horas/año realizadas por los socios trabajadores, con las exclusiones que cita a continuación el art. 80.7.

${ }^{18}$ Entre otras, el art. 11 LETT establece que "Los trabajadores contratados para ser cedidos a empresas usuarias tendrán derecho durante los periodos de prestación de servicios en las mismas a la aplicación de las condiciones esenciales de trabajo y empleo que les corresponderían de haber sido contratados directamente por la empresa usuaria para ocupar el mismo puesto", entendiéndose por condiciones esenciales las referidas a remuneración, duración de la jornada, horas extraordinarias, periodos de descanso, trabajo nocturno, vacaciones y días festivos. La remuneración comprenderá -continúa- todas las retribuciones económicas, fijas o variables, establecidas para el puesto de trabajo a desarrollar, en el convenio colectivo aplicable a la empresa usuaria, que estén vinculadas a dicho puesto de trabajo. Estas retribuciones deberán consignarse en el contrato de puesta de disposición del trabajador. Esta norma y otras, fueron incorporadas con la Ley 29/1999 de 16 de julio tras constatar que las ETT no sólo eran un medio para atender necesidades temporales de las empresas usuarias, sino que, constituían un medio para reducir los costes salariales, como dice en su exposición de motivos; pero las modificaciones introducidas en 1999 no afectaron a la Disposición Adicional Tercera de la Ley anteriormente comentada y que afecta a las ETT constituidas como CTA. 
Seguridad Social, pudiendo los anteriores además, adquirir la condición de trabajadores fijos, a su elección, en cualquiera de dichas empresas.

La jurisprudencia del Tribunal Supremo reconoce la legalidad del contrato de arrendamiento de obras y de prestación de servicios ${ }^{19}$ como forma de realizar la actividad descentralizada de una empresa, y viene a reconocer que no existe cesión ilegal de trabajadores si junto con la mano de obra se aportan otros elementos personales y materiales; se asume el riesgo de la actividad y la capacidad de dirección y selección de personas no está fuertemente limitada. Además debe tenerse en cuenta- se añade- que hay empresas de "actividad simple" donde la aportación de elementos personales y materiales más allá de la prestación de los trabajadores es muy reducida, como en el caso de las empresas de limpieza y vigilancia ${ }^{20}$.

El hecho de que la empresa cedente de mano de obra sea una cooperativa permite al Tribunal presumir que no hay explotación de mano de obra por apropiación de parte de los beneficios de un tercero que nada aporta a la realización del servicio, sino que por el contrario, siendo una cooperativa, los resultados de la explotación pertenecen a sus socios y tienen derecho a su distribución una vez atendidas las reservas obligatorias, salvo que los socios en asamblea general decidan dar otra aplicación a los beneficios.

La determinación de la existencia o no de cesión ilegal de mano de obra por parte de la cooperativa estará condicionada por tanto no sólo a la concurrencia de los anteriores presupuestos sino también a que la citada cooperativa no sea una falsa cooperativa.

La jurisprudencia no toma en consideración que la cooperativa, en los casos enjuiciados, no desarrolla ninguna actividad económica que no sea la de ceder a sus socios trabajadores, lo que la aproxima más a una ETT. Por el contrario, el Tribunal llega a interpretar que precisamente prestar servicios a terceros es la razón de ser de las CTA y se fundamenta en la definición de CTA de la Ley catalana aplicable al caso. Según ésta, las CTA "asocian a personas

\footnotetext{
${ }^{19}$ Que se fundamenta según el Tribunal Supremo en el Código Civil (art. 1588 y 1583) y en el principio constitucional de libertad de empresa (art. $38 \mathrm{CE}$ ).

${ }^{20}$ En el caso de la Sentencia del Tribunal Supremo (STS en lo sucesivo) de 17 de diciembre de 2001 (Rec no 244/2001) el Tribunal estimó que la cooperativa cedente era una empresa real, con más de 2000 trabajadores, que tenía una organización propia que pone al servicio de la empresa cesionaria (Jefes de equipo de la cooperativa que imparten órdenes a los socios trabajadores; herramientas propias de los socios y espacio a su disposición (contratado) en las instalaciones del cesionario). Esta sentencia ha sentado jurisprudencia al ser seguida por otras sentencias posteriores tanto del Tribunal Supremo como de instancias inferiores.
} 
físicas que, mediante su trabajo, se proponen ejercer alguna actividad económica o profesional para terceros" ${ }^{\prime 2}$. Se trata de una definición insuficiente porque no destaca que la cooperativa es una empresa y que es la actividad económica que desarrolla, la generadora de puestos de trabajo para sus socios. En el mismo sentido, la sentencia del Tribunal Superior de Justicia de Cataluña, de 30 de noviembre de 2017 califica de cesión ilegal de trabajadores a la cooperativa Servicarne, pero porque la trabajadora cedida en cuestión no era socia de la cooperativa, porque, aunque lo había solicitado no hubo resolución expresa como exige la ley, por lo que entiende el Tribunal que no adquirió la condición de socia y por tanto su cesión fue ilegal, a diferencia de si hubiera sido socia trabajadora, como había manifestado el Tribunal Supremo en la sentencia citada anteriormente ${ }^{22}$.

Esta jurisprudencia no ha sido bien recibida por la doctrina ni por el movimiento sindical, que han seguido denunciando el proceder de estas cooperativas, calificándolas de falsas ${ }^{23}$. En los últimos años, la Inspección de Trabajo ha sancionado a varias cooperativas de este tipo, incluida aquella cuya actuación fue declarada conforme a derecho en la sentencia del Tribunal Supremo comentada (Servicarne). Como consecuencia de estas sanciones, en unos casos se ha descalificado administrativamente a la cooperativa (Servicarne) por ser una falsa cooperativa ${ }^{24}$ o se ha archivado el expediente de descalificación al optar la cooperativa por disolverse (Cooperativa Agrupación

${ }^{21}$ Art. 101.1 del Decreto Legislativo $1 / 1992$ de 10 de febrero por el que se aprueba el Texto Refundido de la Ley de Cooperativas de Cataluña. A pesar de que esta ley ha sido derogada por otra posterior, la nueva Ley de Cooperativas de Cataluña 12/2015 de 9 de julio, no sólo mantiene la misma definición de CTA sino que incorpora un segundo párrafo según el cual se entiende por actividad cooperativizada en las CTA (esto es, la actividad típica y propia de las cooperativas) "el trabajo que prestan en ella los socios trabajadores y los trabajadores con contrato de trabajo" siempre que no superen ciertos porcentajes (art. 130 LCC); lo que introduce más confusión al equipar el trabajo autogestionado con el trabajo asalariado.

${ }^{22}$ Como dice expresamente la sentencia: "nos hallamos, como acertadamente señala el Juez "a quo" ante una cesión ilegal de trabajadores en el concreto caso de la demandante, al no venir amparada su prestación laboral en la empresa arrendataria del servicio por la condición de cooperativista de la misma".

${ }^{23}$ El sindicato Comisiones Obreras ha publicado un Informe en Julio 2019, en el que da cuenta de las actuaciones emprendidas para combatir los falsos autónomos y las falsas cooperativas

(https://www.ccoo.es/descargas/20190710 SEyCPDEF PROPUESTAS\%20DE\%20ACTUACI\%C 3\%93N falsos\%20autonomos.pdf).

24 https://galicia.economiadigital.es/directivos-y-empresas/trabajo-declara-a-servicarneuna-falsa-cooperativa 622391 102.html 
de Desarrollo Agropecuario) ${ }^{25}$; mientras que en otros casos, la sanción ha sido recurrida ante los tribunales, con resultados diversos según los casos. Las sentencias de los Juzgados de lo Social de Lugo y Orense (en Galicia) y Vitoria (en País Vasco) desestimaron las denuncias rechazando que existiera una cesión ilegal de trabajadores ${ }^{26}$. Por el contrario, las sentencias del Tribunal Superior de Justicia de Coruña no 6125 de 5 de noviembre de 2019, y del Juzgado de lo Social de León no 785 también de noviembre de 2019 han admitido las demandas de la socia trabajadora cedida en el primer caso, y de la Tesorería General de la Seguridad Social en el segundo, contra la empresa cesionaria de los trabajadores de la cooperativa, por considerar que existía relación laboral entre aquella y los socios trabajadores cedidos ${ }^{27}$. La sentencia del TSJ de Coruña absuelve a la cooperativa y considera a la empresa cesionaria como auténtica empleadora del trabajador.

Las irregularidades detectadas en relación con este tipo de cooperativa, han sido, en nuestra opinión, las siguientes. Por una parte, el reconocimiento legal de cooperativas ETT, cuya actividad económica consiste en ceder a sus socios trabajadores, y no haber extendido a estos las mismas garantías que la ley exige en favor de los demás trabajadores cedidos, de forma que no se le apliquen condiciones menos favorables que las que se aplican a los trabajadores propios de la empresa cesionaria. Por otra parte, el criterio judicial al no reconocer el supuesto como cesión ilegal de trabajadores, a pesar de constatar que la cooperativa no desarrolla ninguna actividad económica más allá de ceder sus socios trabajadores. También habría que añadir que esta interpretación se apoya en una norma legal que no describe con acierto qué es la cooperativa de trabajo asociado (Ley catalana de cooperativas, incluso la vigente de 2015). Así, en lugar de decir que la finalidad de la cooperativa es proporcionar a sus socios puestos de trabajo, mediante su esfuerzo personal o directo, a través de la organización en común de la producción de bienes o servicios para terceros, dice que son los socios los que "se proponen producir bienes o prestar servicios para terceras personas". Y es precisamente, esta idea equivocada de la cooperativa de trabajo asociado, en la que se apoyan las

\footnotetext{
25 https://diario16.com/cae-la-primera-falsa-cooperativa-de-la-industria-carnica/

${ }^{26}$ https://galicia.economiadigital.es/directivos-y-empresas/falsos-autonomos-coren-y-cogalganan-la-partida-a-trabajo 651743 102.html. Se da la circunstancia en los casos de denuncias en Galicia, que las empresas cesionarias de los trabajadores son a su vez cooperativas de productores (Coren y Cogal).

${ }^{27}$ http://www.castillayleon.ccoo.es/noticia:406547--

Un juzgado de Leon declara la existencia de relacion laboral de los falsos cooperativi stas de Servicarne en Embutidos Rodriguez
} 
empresas para justificar que es lo propio de la cooperativa, que sus socios presten servicios para terceras personas.

\section{Las cooperativas de transporte de mercancías por carretera}

En relación con las cooperativas de transporte también se han señalado algunos supuestos de falsas cooperativas. Las irregularidades detectadas están relacionadas con los requisitos legalmente exigidos para ser transportista y con la diferenciación entre cooperativa de trabajadores del transporte y cooperativa de transportistas.

La realización del mercado interior del transporte por carretera en la Unión Europea, en condiciones de competencia legal, ha exigido aplicar normas comunes para el acceso a la profesión de transportista. Estas normas se contienen actualmente en el Reglamento (CE) no 1071/200928. Según esta normativa, la profesión de transportista de mercancías por carretera, es aquella actividad realizada por medio de una empresa que transporta mercancías por cuenta ajena. La empresa transportista puede ser de una persona física o jurídica y deberá estar autorizada para el ejercicio de la actividad profesional por la autoridad competente. Los requisitos exigidos para ejercer la profesión de transportista por carretera conforme a la normativa europea son: tener un establecimiento efectivo y fijo en un Estado miembro; gozar de honorabilidad; poseer capacidad financiera apropiada y tener la competencia profesional requerida ${ }^{29}$. Toda empresa de transporte debe tener

\footnotetext{
${ }^{28}$ Reglamento (CE) no 1071/2009 del Parlamento Europeo y del Consejo, de 21 de octubre de 2009 por el que se establecen las normas comunes relativas a las condiciones que han de cumplirse para el ejercicio de la profesión de transportista por carretera y por el que se deroga la Directiva 96/26/CE del Consejo.

${ }^{29}$ La Ley española de Ordenación del Transporte Terrestre por Carretera de 31 de julio de 1987 (LOTT en lo sucesivo), de conformidad con la normativa europea señala que, únicamente podrá contratar la realización de servicios de transporte terrestre de mercancías en concepto de porteador, y emitir facturas en nombre propio por su prestación, quien previamente sea "titular de una licencia o autorización" que habilite para realizar transportes de esta clase o, de una autorización de operador de transporte de mercancías (art. 22 LOTT). La autorización la otorga la Administración Pública al solicitante que acredite ciertos requisitos previstos en la ley, entre otros: disponer de un establecimiento y equipamiento administrativo y técnico suficiente; honorabilidad; capacidad financiera (9.000 euros si se utiliza un vehículo y 5.000 euros más por cada vehículo adicional) y competencia profesional (contar con al menos una persona física que ejerza las funciones de gestor de transporte para lo que deberá estar en posesión del certificado que acredita su competencia profesional para el transporte, tener un vínculo real con la empresa y cumplir el requisito de honorabilidad, además de dirigir efectiva y permanentemente las actividades
} 
un gestor de transporte que cumpla con los requisitos de honorabilidad y competencia profesional, que será quien dirija efectivamente y permanentemente las actividades de transporte de la empresa. El gestor debe ser una persona física vinculada con la empresa, puede ser empleado, director, propietario, accionista, socio o administrador de la empresa.

El transportista es el empresario del transporte, es decir la persona física o jurídica que en nombre propio, por si o por medio de otro, desarrolla la actividad de transporte de mercancías para terceros, de conformidad con la legislación aplicable. Cuando el transportista es una persona física puede desarrollar la actividad de transporte directa y personalmente, o por medio de otra persona. En el primer caso, al empresario individual se le conoce también como trabajador autónomo del transporte, porque, además de asumir el coste y riesgo de la actividad, y la responsabilidad propia del empresario, emplea su trabajo personal en el desarrollo de la actividad ${ }^{30}$.

Es frecuente en la práctica que un trabajador autónomo realice en exclusiva o en su mayor parte, la actividad de transporte para un solo cliente. Este supuesto, que en España se conoce como trabajador autónomo económicamente dependiente (TRADE en lo sucesivo) está expresamente previsto y regulado en el Estatuto del Trabajador Autónomo (ETA en lo sucesivo) y en el Estatuto de los Trabajadores (ET). El trabajador autónomo económicamente dependiente se define como aquél que realiza una actividad económica o profesional a título lucrativo y de forma habitual, personal, directa y predominante para una persona física o jurídica, denominada cliente, del que depende económicamente por percibir de él, al menos, el 75 por ciento de sus ingresos por rendimientos de trabajo y de actividades económicas 0 profesionales (art. 11 ETA). A pesar de esa dependencia económica, el TRADE no deja de ser un empresario individual, sobre todo porque asume los costes, riesgos y responsabilidades de la gestión, además de tener la titularidad o disponibilidad de los bienes necesarios para ejercer su actividad. Por ello el

de transporte (arts. 44 a 47 LOTT). Así mismo, quienes contraten una operación de transporte como porteadores deberán llevarla a cabo a través de "su propia organización empresarial", esto es con vehículos de su propiedad o en arrendamiento (ordinario o financiero); salvo que actúen como meros intermediarios (art. 54 LOTT).

${ }^{30}$ La Ley 20/2007, de 11 de junio sobre el Estatuto del Trabajador Autónomo, es de aplicación a las personas físicas que realicen de forma habitual, personal, directa, por cuenta propia y fuera del ámbito de dirección y organización de otra persona, una actividad económica o profesional a título lucrativo, den o no ocupación a trabajadores por cuenta ajena. Esta actividad autónoma o por cuenta propia podrá realizarse a tiempo completo o a tiempo parcial (art. 1.1. ETA). 
legislador excluye al trabajador autónomo económicamente dependiente de la aplicación del Estatuto de los Trabajadores (art. $1.3 \mathrm{f}$ ET), y en particular, a quienes prestan el servicio de transporte al amparo de autorizaciones administrativas de las que sean titulares, y con vehículos cuya propiedad o poder directo de disposición ostenten, aun cuando dichos servicios se realicen de forma continuada para un mismo cargador o comercializador (art. 1.3 in fine ET).

Como dice la legislación española, la cooperativa puede organizar y desarrollar cualquier actividad económica lícita (art. 1.2 LCE) y por ello también, puede desarrollar cualquier actividad en el sector del transporte. En España la cooperativa actúa normalmente como transportista, como agencia de transporte o como empresa de servicios complementarios al transporte. En el primer caso la cooperativa adopta la forma de CTA y se conoce como cooperativa de transporte; mientras que en los demás supuestos adopta la forma de cooperativa de servicios y se denomina cooperativa de transportistas. También se contempla expresamente la cooperativa mixta o integral formada por socios trabajadores y socios transportistas.

El sector del transporte de mercancías por carretera ha sido tradicionalmente un sector muy atomizado formado por pequeñas empresas propiedad de trabajadores autónomos que con sus vehículos desarrollaban la actividad de transporte para uno o varios clientes; por ello su integración en cooperativas siempre se ha visto como una mejora ${ }^{31}$. Por una parte, porque aquellos que no reunían los requisitos para obtener la autorización administrativa, podían integrarse en una cooperativa de transporte que sí disponga de tal autorización, de forma que puedan seguir prestando servicios de transporte aunque en este caso en nombre de la cooperativa ${ }^{32}$. Por otra

\footnotetext{
${ }^{31}$ Según la exposición de motivos de la LOTT "La Ley contribuye a ... potenciar a las empresas que intervienen en dicho sector, a través de un amplio abanico de medidas entre las cuales figuran .... la previsión de la constitución de cooperativas y la realización de otras formas de colaboración entre transportistas, uniéndose entre sí para crear canales de comercialización y oferta de transportes, de una dimensión adecuada, paliando así la situación de atomización, que es uno de los principales problemas con los que se enfrenta el sector".

${ }^{32}$ Esta posibilidad quedó reflejada en la Ley Valenciana de Cooperativas 11/1985 al describir la Cooperativa de transporte como aquella que agrupa a transportistas, conductores $\mathrm{u}$ otro personal con el fin de llevar a cabo el objeto social, y contempla la aportación de su vehículo al capital social de la cooperativa y su posible recuperación al causar baja de la cooperativa, si reúne los requisitos conforme a la legislación vigente para ser transportista. Así mismo se contempla que los Estatutos puedan tomar en cuenta en la determinación y aplicación de resultados, los ingresos y gastos que genere la explotación de cada vehículo (art. 80 LCCV 1985).
} 
parte, aquellos que sí disponían de la correspondiente autorización, podían mejorar sus empresas y clientela integrándose en una cooperativa de transportistas que les ofrezca compras y servicios conjuntos, y nuevas oportunidades de negocio, actuando la cooperativa como agencia de transporte ${ }^{33}$.

La cooperativa de transporte puede tener su origen, a partir de trabajadores que se unen para prestar servicios de transporte poniendo en común su trabajo y fondos suficientes para adquirir o arrendar vehículos de transportes y otras instalaciones, que como vimos son necesarias. Pero también puede tener su origen a partir de la unión de personas que venían realizando la actividad de transporte como trabajadores autónomos pero no disponen, o han perdido, la autorización administrativa necesaria. En este caso, los socios no sólo ponen en común su trabajo y fondos, sino también los vehículos y la clientela entre otros bienes. Es en este caso donde tradicionalmente se han planteado problemas, cuando los socios de la cooperativa de transporte pretenden, bajo el amparo de la autorización de la cooperativa, seguir desarrollando su actividad como transportistas, contratando y facturando en nombre propio los transportes que sólo podrían realizarse en nombre de quien tiene la autorización administrativa para ello, esto es, en nombre de la cooperativa. De ahí la insistencia del art. 22 LOTT cuando dice que "Únicamente podrá contratar la realización de servicios de transporte terrestre de mercancías en concepto de porteador, y emitir facturas en nombre propio por su prestación, quien previamente sea titular de una licencia o autorización que habilite para realizar transportes de esta clase o, en otro caso, de una autorización de operador de transporte de mercancías", y sanciona su incumplimiento como infracción muy grave ${ }^{34}$. En el mismo sentido la Ley 15/2009, de 11 de noviembre, del contrato de transporte terrestre de mercancías (LCTTM) establece que las cooperativas de trabajo asociado

\footnotetext{
${ }^{33}$ Las cooperativas como cualquier otra empresa que pretenda intermediar en la contratación de transporte de mercancías por carretera debe obtener una autorización como operador de transporte. Sin embargo, las cooperativas de transportistas, si limitan su intermediación a la comercialización de los transportes prestados por sus socios transportistas, no necesitan obtener dicha autorización (art. 119.1 LOTT).

${ }^{34} \mathrm{El}$ art. 140.2 LOTT no sólo califica como infracción muy grave la contratación como porteador o la facturación en nombre propio de servicios de transporte sin ser previamente titular de autorización de transporte, sino que aplica la misma calificación a una mala praxis que venían haciendo los trabajadores de cooperativas de transporte, consistente en contratar y facturar en nombre propio la prestación de servicios de transporte a la propia cooperativa de transporte de la que forman parte sin ser ellos mismos, a su vez, titulares de tal autorización.
} 
dedicadas al transporte, sólo podrán contratar éstos en nombre propio (art. 5.2 LCTTM), y sus socios sólo podrán contratar transportes en nombre de la cooperativa a la que pertenecen, quedando ésta obligada como porteador frente al cargador con quien contraten aquéllos (arts. 5. 3 LCTTM).

Por tanto, cuando la empresa se constituya como cooperativa de transporte, será esta la que deba cumplir con los requisitos exigidos para ejercer la actividad del transporte, la que obtenga la autorización administrativa necesaria, tenga la propiedad o disposición de los vehículos necesarios, y la que contratará y facturará en su nombre los servicios de transporte que preste, los cuales deberán realizarse como exige la legislación cooperativa, con el trabajo mayoritario de sus socios ${ }^{35}$. No importando por lo demás si los vehículos han sido aportados a capital por los socios, o arrendados por la cooperativa a éstos o a terceros ${ }^{36}$. La garantía financiera la cumple la cooperativa disponiendo de capital y reservas por un importe mínimo de 9.000 euros, cuando se utilice un solo vehículo y de 5.000 euros más por cada vehículo adicional utilizado (art. 46 LOTT).

Sin embargo, recientes sentencias en España han cuestionado la actividad desarrollada por algunas cooperativas de transporte, por el hecho de que los vehículos utilizados para realizar el transporte no eran de su propiedad sino que habían sido arrendados, y que el cliente (cargador) era el que se ponía en contacto directo con el conductor (socio de la cooperativa) para encomendarle los servicios que debía realizar (indicándole el origen de la carga y su destino, así como la fecha de carga y de descarga, según los hechos probados que se citan). Además, el Tribunal Supremo en sentencia 2263/2018, de 18 de mayo, interpreta que el socio de una CTA al no disponer de autorización ni de vehículo de transporte, no es un verdadero autónomo y no puede acogerse a la exención del art. 1.3 in fine del Estatuto de los Trabajadores, que vimos anteriormente; y concluye por ello, que su relación con el cargador debe calificarse como laboral. Es una conclusión que no puede compartirse. El Tribunal no toma en consideración la existencia de un contrato de transporte entre la cooperativa y el cliente; ni que la condición de

\footnotetext{
${ }^{35}$ La LCE señala que el número máximo de horas/año realizadas por trabajadores de la cooperativa con contrato de trabajo por cuenta ajena no podrá ser superior al 30 por 100 del total de horas/año realizadas por los socios trabajadores (art 80.7).

${ }^{36}$ Como dice la LOTT quienes contraten una operación de transporte como porteadores deberán llevarla a cabo a través de su propia organización empresarial (art. 54.1 LOTT); y se entiende que los vehículos utilizados se hallan integrados en la organización empresarial del porteador cuando disponga de ellos en propiedad, arrendamiento financiero 0 arrendamiento ordinario (art. 54.2 LOTT).
} 
transportista es de la cooperativa y no de sus socios trabajadores; así mismo, tampoco tiene en cuenta que por el contrato de transporte la cooperativa se obliga a un resultado (trasladar la mercancía de un lugar a otro) y no a prestar servicios.

No es una irregularidad que la cooperativa arriende un vehículo para hacer el transporte, aunque este sea propiedad del cargador; tampoco lo es que el cargador de instrucciones al socio trabajador sobre el origen de la carga y su destino, o la fecha de carga y de descarga; es más, son instrucciones necesarias para poder cumplir el contrato (art. 10 LCTTM). Hemos visto incluso como es habitual, y se reconoce expresamente en la ley, que los socios trabajadores de las cooperativas sean los que contraten con el cargador, siempre que el contrato de transporte se haga en nombre de la cooperativa (art. 5.3 LCTTM).

Los socios de la cooperativa de trabajo asociado del transporte no son transportistas sino trabajadores asociados en cooperativa, y como tales llevan a cabo la actividad propia del objeto social de ésta, esto es, realizan transportes en nombre de la cooperativa y por cuenta de terceros (cargadores). Sin embargo, el Tribunal tras comprobar que el trabajador no tiene la condición de profesional del transporte, por no disponer de la necesaria autorización administrativa, concluye que su relación debe considerarse laboral, sin tomar en consideración que se trata del socio de una cooperativa de trabajo asociado.

En la demanda que da origen al caso comentado se solicita por el socio de la cooperativa la declaración de despido improcedente. El socio de la cooperativa, tras comunicar a ésta su baja por incapacidad temporal, ofrece sus servicios directamente al cliente, quien no responde a su ofrecimiento, ni más tarde la cooperativa vuelve a asignarle ningún trabajo. La sentencia de instancia, que confirma más tarde el Tribunal Supremo, declara improcedente el despido y condena solidariamente a la cooperativa y a su cliente a readmitir al trabajador con abono de los salarios de tramitación, o a que le indemnicen por la extinción de la relación laboral, declarando al Fondo de Garantía Salarial responsable subsidiario de dichos pagos.

Si bien no advertimos irregularidades significativas en la actividad desarrollada por la cooperativa como empresa transportista, sí existen por su condición de cooperativa. El Tribunal en cambio, no repara en ello hasta el último momento y no extrae de ello todas las consecuencias que cabría esperar. La principal irregularidad que se observa al respecto es que los socios que trabajan como conductores en la cooperativa de trabajo asociado, son socios colaboradores y no socios cooperadores. Los socios colaboradores 
pueden "colaborar" con la cooperativa, normalmente aportando capital, pero en ningún caso pueden participar en la actividad que desarrolla el objeto social de la cooperativa ${ }^{37}$. Sin embargo, en el caso analizado, los socios colaboradores están participando en la actividad cooperativa prestando su trabajo, como si fueran socios trabajadores y como éstos cotizan al régimen de autónomos en la Seguridad Social; sin embargo sus derechos políticos son los propios de los socios colaboradores, y por tanto limitados a no superar el $30 \%$ de los votos en los órganos sociales de la cooperativa (art. 14.3 LCE). En consecuencia, nos encontramos con una cooperativa que cuenta con dos tipos de socios: tres socios trabajadores que tienen el control de la cooperativa y 115 socios colaboradores que han pagado como socios para acceder a un trabajo; constan ante la SS como si fueran socios trabajadores de una CTA, pero no tienen capacidad de autogestión, estando incluso en clara dependencia respecto de los calificados como socios trabajadores. Se trata por tanto de un claro incumplimiento de la legislación cooperativa y de la Seguridad Social que tiene como objeto perjudicar a los trabajadores calificados de socios colaboradores. No siendo éstos socios trabajadores, su prestación de trabajo sólo puede calificarse como laboral respecto de la cooperativa que es para quien trabajan, y por tanto, sometidos a la legislación laboral y de Seguridad Social correspondiente (régimen general).

\section{Medidas adoptadas por el poder público en España para combatir las falsas cooperativas de trabajadores}

Las falsas cooperativas de trabajadores son un tema de actualidad en los medios de comunicación en España, en los últimos años; pero falsas cooperativas han existido siempre y siempre se han perseguido por la administración pública. La Inspección de Trabajo tiene como cometido la vigilancia y exigencia del cumplimiento de las normas legales, reglamentarias y del contenido de los acuerdos de las cooperativas ${ }^{38}$, y la autoridad administrativa en materia de empleo tiene la potestad de sancionar a las

\footnotetext{
${ }^{37}$ Como dice el art. 14. 1 LCE "Los Estatutos podrán prever la existencia de socios colaboradores en la cooperativa, personas físicas o jurídicas, que, sin poder desarrollar $o$ participar en la actividad cooperativizada propia del objeto social de la cooperativa, pueden contribuir a su consecución".

${ }^{38}$ Arts. $12.1 \mathrm{f}$, y $19.1 \mathrm{f}$, de la Ley $23 / 2015$ de 21 de julio Ordenadora del Sistema de Inspección de Trabajo y Seguridad Social.
} 
cooperativas por las infracciones cometidas ${ }^{39}$, pudiendo incluso intervenirla temporalmente ${ }^{40}$ o descalificarla, lo que implicará su disolución ${ }^{41}$.

Pero al margen de estas medidas sancionadoras, el legislador también ha tratado de prevenir situaciones de abuso con medidas legales más o menos concretas. Medidas generales como puede ser extender a los socios trabajadores los derechos que la legislación laboral reconoce a los trabajadores dependientes, o medidas concretas para el caso en que una cooperativa se encuentre en una situación de dependencia con respecto a un cliente o proveedor.

La extensión de aspectos de la legislación laboral a los socios trabajadores de cooperativas se da a partir de la Ley de Cooperativas de 1974, que incorpora un capítulo titulado "Régimen Laboral", y de la sentencia del Tribunal Supremo de 4 de junio de 1974 (RA. 2005). La primera extiende a los socios trabajadores el régimen general de la Seguridad Social, al que pueden optar estatutariamente, y somete los conflictos entre socios y cooperativas por cuestiones relativas a la prestación del trabajo, a la Jurisdicción de lo Social. La segunda califica de laboral la relación entre la cooperativa y sus socios trabajadores porque en su opinión existe dependencia y ajenidad en la prestación de trabajo del socio. Esta tesis se mantuvo a lo largo de los años setenta sobre todo en las sentencias del Tribunal Central de Trabajo. A partir de los años ochenta, se renueva la legislación cooperativa, se reconoce ampliamente la capacidad de autogestión de los socios y la jurisprudencia define la relación entre cooperativa y socios trabajadores como "societaria", es

\footnotetext{
${ }^{39}$ El Real Decreto Legislativo 5/2000, de 4 de agosto, aprueba el Texto Refundido de la Ley sobre Infracciones y Sanciones en el Orden Social. Entre otras, se consideran infracciones graves la transgresión generalizada de los derechos de los socios, y entre las muy graves, la transgresión de las disposiciones imperativas o prohibitivas de la Ley de cooperativas, cuando se compruebe connivencia para lucrarse o para obtener ficticiamente subvenciones o bonificaciones fiscales (art. 38). A la hora de graduar las infracciones a efectos de su sanción se tendrá en cuenta entre otros elementos el número de socios afectados, la repercusión social de la infracción, la malicia o falsedad empleada o la capacidad económica de la cooperativa (art. 39).

${ }^{40}$ Esta posibilidad ha desaparecido en la Ley estatal de cooperativas pero sigue presente en algunas leyes autonómicas. La intervención puede ser puntual para convocar una asamblea general o temporal, o para nombrar uno o varios administradores provisionales. No obstante, esta medida tiene escasa aplicación, pues como decía PAZ CANALEJO $(1994,903)$ resulta muy ambigua.

${ }^{41}$ Art. 116 LCE. La descalificación podrá tener lugar cuando se den los supuestos previstos en la legislación cooperativa. La resolución administrativa que la declare será revisable por vía judicial y mientras no recaiga sentencia firme no será ejecutiva.
} 
decir, sometida a los acuerdos sociales, como en el resto de cooperativas (STS 19 mayo 1987 RA. 3734 o STS 29 de mayo de 1990, RA. 4516, entre otras). A partir de entonces, el legislador, tanto estatal como autonómico, incorpora expresamente en la legislación cooperativa la naturaleza societaria de esa relación y remite a los estatutos, reglamentos internos y acuerdos sociales la regulación de las condiciones de trabajo de los socios. Tras esta declaración es normal también que se indique qué materias deben regularse por los socios ${ }^{42}, y$ en caso de ausencia de regulación se sometan a la aplicación supletoria de la legislación cooperativa estatal y en última instancia, o por analogía, del derecho laboral (LCPV. Art. 101). Otras legislaciones en cambio han optado por establecer un régimen legal mínimo indisponible para los socios trabajadores, en materias como salud laboral, previsión de riesgos y otros (LCCat. Art. 132).

Otras medidas concretas que podemos encontrar en la legislación para prevenir situaciones de abuso en las cooperativas de trabajadores, son las que se contemplan para el caso de dependencia de la cooperativa respecto de un cliente o proveedor. En este sentido, la Ley valenciana de 2003 incorporó una norma por la que si la cooperativa tiene "más del $80 \%$ de su facturación anual con un único cliente o un único grupo de empresas, el anticipo societario garantizado al socio en cómputo anual deberá ser equivalente al salario medio de la zona, sector y categoría profesional correspondiente" ${ }^{\prime 3}$.

Las falsas cooperativas parecen haberse extendido en los últimos años aprovechando la crisis y el elevado paro que padecemos, al menos eso es lo que reflejan los medios de comunicación. La denuncia de esta situación irregular ha partido principalmente de las propias organizaciones cooperativas y de los sindicatos.

Merece destacarse sobre todo la actuación de los sindicatos para hacer frente a las falsas cooperativas y en particular su eficaz estrategia, que ha consistido en: denunciar a la Inspección de Trabajo los casos más importantes; impulsar demandadas de trabajadores ante la jurisdicción social; convocar huelgas y concentraciones de trabajadores; boicotear los productos de la

\footnotetext{
42 Materias como: a) La forma de organización de la prestación del trabajo. b) La movilidad funcional y geográfica. c) La clasificación profesional. d) El régimen de fiestas, vacaciones y permisos. e) La jornada, turnos y descanso semanal. f) Las causas de suspensión o extinción de la prestación laboral. g) Los anticipos societarios. h) Los demás derechos y obligaciones que, en materia de prestación de trabajo, considere conveniente establecer la cooperativa (art. 89.3 LCCV).

${ }^{43}$ Art. 89.3 de la Ley 8/2003, de 24 de marzo; y en los mismos términos el mismo artículo de la vigente Ley $2 / 2015$.
} 
empresa cesionaria ${ }^{44}$ y renegociar las nuevas condiciones de trabajo para los falsos cooperativistas reinsertados ${ }^{45}$.

Así, tras las denuncias y la labor de la Inspección de Trabajo se ha conseguido que desde el Ministerio de Trabajo o autoridad competente en la Comunidad Autónoma correspondiente, se descalifiquen algunas falsas cooperativas y sus socios trabajadores se integren como trabajadores asalariados de las empresas para las que indirectamente trabajaban ${ }^{46}$. También hemos visto como las sentencias en relación con cooperativas falsas se han multiplicado y comienzan a reconocer relaciones laborales donde aparentemente eran relaciones societarias, aunque la fundamentación jurídica empleada sea discutible. Por último, debe destacarse la presión realizada por los sindicatos para someter a las CTA a la normativa acordada en convenios colectivos aprobados entre patronal y sindicatos, y por procurar su exclusión de determinados sectores económicos ${ }^{47}$. Para llevar a cabo todas estas acciones, los sindicatos reclaman una mayor intervención en las cooperativas de trabajadores. Una de sus propuestas de actuación es precisamente: "hacer una labor sindical de "empresa por empresa", en especial en las cooperativas de trabajo asociado" (pág. 9). Con este fin, tras un recurso planteado por el sindicato CNT contra la cooperativa Servicarne, se ha conseguido que el Tribunal Supremo reconozca, no sólo que "los socios trabajadores de una cooperativa de trabajo asociado tienen derecho a afiliarse libremente al

\footnotetext{
${ }^{44}$ Entre otras mediante el llamado "Semaforo Laboral" como herramienta sindical que informará a los consumidores de la huella laboral de las empresas y sus marcas comerciales, con los colores rojo, amarillo y verde. En otras ocasiones ha sido suficiente con amenazar al empresario cesionario de dicho boicot en el caso de que contrate los servicios de la cooperativa, como en el caso analizado en la sentencia.

${ }^{45}$ Véase el Informe publicado por el sindicato Comisiones Obreras en Julio 2019, en el que da cuenta de las actuaciones emprendidas para combatir las falsas cooperativas, y que citamos en anterior nota a pie de página.

${ }^{46}$ Según BAYLOS (en Blog: "Según Antonio Baylos» de 10 de mayo de 2019). Sin embargo una noticas de la agencia de noticias EFE de 29 de septiembre de 2018 aludía a que de las 54 cooperativas del sector cárnico a las que se había obligado a regularizar el empleo de las casi 5000 personas dadas de alta como autónomos en aquel momento, sólo nueve han pasado a sus trabajadores al régimen general.

${ }^{47}$ En este sentido el Convenio colectivo estatal de industrias cárnicas suscrito el 11/12/2018 y publicado por Resolución de la Dirección General de Trabajo de 19 de marzo de 2019 (BOE 10.04.2019) extiende su ámbito funcional a las CTA que actúen en el sector (art. 3), y en su Disposición adicional primera las partes se comprometen a no contratar con cooperativas de trabajo asociado, por considerar que su utilización no es la solución adecuada para la necesaria estabilidad del empleo en el sector, la formación profesional de los trabajadores, la mejora de la productividad y la competitividad de las empresas.
} 
sindicato de su elección", sino también, "que los sindicatos legalmente constituidos tienen derecho al libre ejercicio de la actividad sindical en las Cooperativas de Trabajo Asociado donde tengan afiliados socios trabajadores de las mismas" (STS no 1944 de 8 de mayo de 2019). Este reconocimiento se obtiene tras una interpretación amplia del art. 28.1 de la Constitución Española ("Todos tienen derecho a sindicarse libremente") y a normas internacionales ratificadas por España, especialmente los Convenios de la OIT no 87 y 98, y la Recomendación 193 de la OIT sobre promoción de las cooperativas. No debe olvidarse que este reconocimiento de la libertad sindical se plantea en un supuesto de cooperativa falsa, donde puede estar justificada la protección sindical de los supuestos socios trabajadores, ante la falta de garantías que tienen para ejercer sus derechos sociales. Sin embargo, la sentencia extiende el derecho del sindicato a ejercer la actividad sindical en todas las cooperativas de trabajadores, lo cual implica permitir que se cree una doble estructura de control al interior de la cooperativa: el control de los socios cooperativos, basada en el principio de igualdad, y el control de los sindicatos en favor de sus socios trabajadores afiliados.

Los sindicatos también presionan al legislador para que tome medidas legales que ponga fin a las cooperativas falsas. Así se dice que las propuestas realizadas van encaminadas a modificar la regulación de las cooperativas para: establecer con carácter general que la relación de los socios trabajadores con la cooperativa sea laboral, o bien distinguir según el número de socios trabajadores de la cooperativa, de forma que, si tiene menos de 10 seguirían siendo una relación societaria, pero si se supera esa cifra los socios trabajadores se considerarían sujetos a una relación laboral y vinculados al convenio colectivo aplicable ${ }^{48}$.

En esta línea se han modificado recientemente las legislaciones cooperativas de Cataluña, Castilla y León, Extremadura y País Vasco. La LCC se modificó por Ley 5/2017 en el sentido de reconocer que una CTA con más de 25 socios trabajadores que tengan por actividad principal la realización, mediante subcontratación mercantil de obras, suministros o servicios de toda o parte de la propia actividad o de la actividad principal de otra empresa o empresas o grupos empresariales contratistas, o que realicen una actividad económica de mercado para un cliente con una dependencia de un $75 \%$ o más de la facturación anual de la cooperativa, los estatutos o el reglamento de régimen interno deben garantizar y recoger obligatoriamente como mínimo: a) las condiciones de trabajo, especialmente en cuanto a la jornada laboral y las

${ }^{48}$ GARCÍA JIMÉNEZ $(2018,208)$. 
retribuciones, y b) la protección social de los trabajadores. Esas condiciones de trabajo deben ser cómo mínimo- dice a continuación- equivalentes a las que reconozcan los convenios colectivos laborales aplicables a los trabajadores por cuenta ajena del sector o centro de trabajo de la empresa principal para la que presten servicios; y la protección social de los socios trabajadores deberá ser equivalente a la de los trabajadores incluidos en el RGSS (art. 132 apartados 5 a 9). En los mismos términos se pronuncian la Ley de Cooperativas de Castilla y León 4/2002 (art. 103) tras su reforma por Ley 2/2018 de 18 de junio; y la Ley 9/2018 de 30 de octubre, de sociedades cooperativas de Extremadura (art. 149.2). Sin embargo, la reforma de la ley catalana no ha alcanzado a modificar la definición de la cooperativa de trabajo asociado, que ha dado lugar a cooperativas como Servicarne, y sigue diciendo que los socios de la CTA "se proponen producir bienes o prestar servicios para terceras personas", en lugar de: "producen en común" bienes o servicios, aunque estos estén destinados a terceros. Si no se define claramente qué es una CTA y qué papel cumplen sus socios trabajadores, no debe extrañar que se sigan constituyendo estas cooperativas para llevar a cabo, precisamente, los fines que la ley les reconoce como propios (que sus socios trabajadores presten servicios a terceros). Las críticas a estas últimas normas no se han hecho esperar al considerar que vulneran los principios de participación y gestión democrática y de independencia de las cooperativas, al aplicar a los socios la regulación laboral propia de los trabajadores por cuenta ajena, menospreciando así su libertad para tomar decisiones sobre cómo organizar su trabajo. $Y$ es que, en efecto, como se dice, ante un fraude de ley como el detectado, no procedía su regulación sino su prohibición ${ }^{49}$. Distinta ha sido la respuesta dada por la Ley de Cooperativas de Euskadi 11/2019, de 20 de diciembre. En este caso, tras recordar que son los estatutos, reglamento de régimen interior y asamblea general, donde se establecerá el marco básico del régimen de trabajo de los socios trabajadores, marca a dicho régimen dos límites: por una parte, las condiciones laborales deben ser dignas, y por otra, hay que respetar los estándares laborales mínimos establecidos por la Organización Internacional del Trabajo (art. 105.3). La solución propuesta parece acertada pero imprecisa lo que puede generar inseguridad jurídica a los socios a la hora de concretar su estatuto jurídico.

El Gobierno de España también ha tomado medidas para luchar contra las cooperativas falsas, en concreto podemos destacar el Acuerdo del Consejo de Ministros por el que se aprueba el Plan Director por un Trabajo Digno (20182019-2020) adoptado el 27 de julio de 2018 (BOE 182, de 28.07.2018). Este

${ }^{49}$ GRAU (2017). 
Plan persigue recuperar derechos laborales, mejorar la calidad del empleo y de las condiciones de trabajo, con el fin de reforzar la sostenibilidad presente y futura de la Seguridad Social y de las prestaciones sociales, y fortalecer la competencia leal entre empresas en el mercado de trabajo. El Plan Director cambia radicalmente la estrategia de la inspección de trabajo y seguridad social para ser más eficaz en la lucha contra el fraude, la precariedad laboral y la erradicación de las situaciones de abuso. Uno de los objetivos del Plan es la lucha contra la utilización de forma fraudulenta de la cooperativa para aprovecharse del derecho que la normativa les concede en cuanto al régimen de seguridad social aplicable a los socios trabajadores de las CTA.

Más allá de este Plan y de la estrategia de inspección, la normativa estatal no ha adoptado medidas legales para prevenir o sancionar a las cooperativas falsas. El 92 de febrero de 2018 el Grupo Parlamentario Unidos Podemos y sus asociados (En Comú Podem y En Marea) presentaron una Proposición de Ley ${ }^{50}$ que pretendía "revertir la situación de precariedad de los trabajadores y trabajadoras que, desde su vinculo formal con cooperativas de trabajo asociado, prestan servicios en las industrias cárnicas y mataderos de aves y conejos", como dice su título. Con dicha proposición pretendían modificar el Estatuto de los Trabajadores, la Ley General de la Seguridad Social y la Ley de Cooperativas, para reconocer a los socios trabajadores de estas cooperativas que prestan servicios para otras empresas, los mismos derechos sociales que si fueran trabajadores asalariados. Esta proposición de ley no prosperó, pero la posición del grupo parlamentario de Podemos sobre el tema es importante ya que en la composición del nuevo Gobierno de España tras las elecciones de noviembre de 2019, y el reparto de carteras entre el Partido Socialista y Podemos, el Ministerio de Empleo será gestionado por este último partido. ${ }^{51}$

\footnotetext{
${ }^{50}$ Boletín Oficial de las Cortes Generales. Congreso de los Diputados, de 9 de febrero de 2018.

${ }^{51}$ Entre las propuestas que Podemos incorporó a su Programa de Gobierno para las elecciones de Noviembre de 2019 cabe destacar las siguientes: a) Poner orden en la subcontratación y proteger los derechos laborales de los trabajadores en subcontrata, por una parte, limitando la subcontratación a servicios especializados ajenos a la actividad principal de la empresa, de manera que los servicios propios de la empresa queden excluidos; y por otra, estableciendo que cuando la subcontratación esté justificada, sus trabajadores tendrán las mismas condiciones de trabajo que la empresa matriz (166); b) Fin del fraude de los falsos autónomos, presumiendo que existe una relación laboral por cuenta ajena cuando la persona autónoma tenga una única vía de ingresos relevante, y obligando a la empresa a incorporar a esa persona con un contrato indefinido y a abonar su afiliación a la Seguridad Social (173), y por último c) Estableciendo cuotas justas para los autónomos, de
} 


\section{Conclusiones}

Tras el análisis de los supuestos de cooperativas que en estos momentos se cuestionan en España y se identifican como falsas cooperativas, hemos visto como la reacción está siendo por una parte la de intensificar la inspección de las CTA que prestan servicios para otras empresas; y por otra, incorporar reformas legales para restringir los derechos de autogestión de aquellas cooperativas. En nuestra opinión estas no son las mejores vías para combatir las falsas cooperativas, como tampoco que se ejerza la acción sindical en el interior de las cooperativas.

En cambio, consideramos que existen normas jurídicas que promueven la constitución de falsas cooperativas y no sólo no se suprimen sino que se reproducen. Entre estas hemos hecho referencia a la concepción errónea que de la cooperativa de trabajo asociado tiene la Ley catalana de cooperativas y que justifica la creación de cooperativas para que sus socios trabajadores presten servicios a terceros. También hemos criticado las cooperativas en las que conviven dos tipos de socios, y los socios trabajadores no tienen capacidad para regular su estatus profesional. En estos casos, los socios trabajadores deben recuperar los derechos propios de los trabajadores dependientes, porque es lo que son. Téngase en cuenta que el marco jurídico aplicable al socio trabajador de una cooperativa parte del presupuesto de que son los socios trabajadores quienes tienen la capacidad de decidir como colectivo, tanto la actividad a realizar como las condiciones en que lo harán, y por ello tienen la responsabilidad empresarial de sus decisiones, por lo que se les asimila en muchos aspectos a los trabajadores autónomos; pero no puede ser que se les prive de la capacidad de autogestión y no de la responsabilidad derivada. Algo parecido pasa con el socio colaborador cuando se permite que participe en la actividad cooperativa. Si este socio participa prestando servicios en una cooperativa, debe ser considerado como un trabajador dependiente y nunca como un socio cooperador.

Una mención especial merece la regulación de la cesión de trabajadores en el Estatuto de los Trabajadores y su aplicación a las cooperativas de trabajo asociado. Como hemos visto, una cooperativa de trabajo asociado puede tener como actividad principal ceder trabajadores (socios o no) a otras empresas,

forma que sólo coticen por los rendimientos que realmente obtengan (174). Esta última medida permitiría combatir las cooperativas de facturación, creadas para que los trabajadores autónomos puedan acogerse al régimen general de la seguridad social, más flexible que el régimen de autónomos (https://podemos.info/wpcontent/uploads/2019/10/Podemos programa generales 10N.pdf). 
pero en ese caso debe constituirse como Empresa de Trabajo Temporal. Las ETT contribuyeron a la reducción de los salarios de los trabajadores, por ello se modificó la ley para exigir que los trabajadores cedidos tendrían derecho durante los periodos de prestación del servicio a las mismas condiciones esenciales de trabajo y empleo que les corresponderían de haber sido contratados directamente por la empresa cesionaria para ocupar el mismo puesto. Esta medida que parece razonable, no es de aplicación en cambio para los trabajadores (socios) cedidos por la cooperativa, porque estos están expresamente excluidos de esa garantía (Disposición Adicional Tercera Ley 29/1999). Normas como ésta abocan a utilizar las CTA para rebajar salarios y condiciones de los trabajadores y deberían suprimirse. Por otra parte, si una CTA contrata con una empresa la prestación de servicios y se da alguna de las circunstancias que determina el art. 43 del Estatuto de los Trabajadores, podrá considerarse cesión ilegal de trabajadores, en cuyo caso, se aplicarán las consecuencias previstas, que afectan tanto a la empresa cedente (cooperativa o no) como a la empresa cesionaria, ambas responderán solidariamente de las obligaciones contraídas con los trabajadores y con la seguridad social. Pudiendo los trabajadores cedidos optar por adquirir la condición de trabajador fijo de la empresa cesionaria con las mismas condiciones que tendría un trabajador que preste servicios en el mismo o equivalente puesto de trabajo, si bien la antigüedad se computará desde el inicio de la cesión ilegal.

Al margen de los anteriores supuestos, hemos visto como se está regulando en las leyes de cooperativas el supuesto en el que una cooperativa preste servicios a otra empresa, con la que tenga una relación de dependencia económica porque represente una parte sustancial de sus ingresos (75 o más de su facturación). En estos casos, quiere el legislador que las condiciones de trabajo del socio que lleva a cabo el servicio sean como mínimo las indicadas por el convenio colectivo aplicable a los trabajadores asalariados del sector o centro de trabajo donde presta sus servicios, y la protección social sea equivalente a la que tienen los trabajadores incluidos en el RGSS. Esta norma debería desincentivar la utilización de cooperativas para evitarse los costes laborales y sociales de los propios trabajadores, pero no presupone que estemos ante una falsa cooperativa, sino mas bien, lo que se pretende es evitar la tentación de recurrir a la contratación de servicios con cooperativas, en lugar de contratar el personal laboral que necesite la empresa.

Una cooperativa falsa, sea de trabajo asociado o de otro tipo, evoca un supuesto fraudulento, en el que la cooperativa se ha constituido con el fin de obtener un resultado prohibido por ley. En estos casos es de aplicación el Código Civil, cuyo artículo 6.4 establece que "Los actos realizados al amparo del texto de una norma que persigan un resultado prohibido por el ordenamiento 
jurídico, o contrario a él, se considerarán ejecutados en fraude de ley y no impedirán la debida aplicación de la norma que se hubiere tratado de eludir"; en consecuencia, si el objetivo al constituir la cooperativa no era satisfacer en las mejores condiciones posibles las necesidades de sus socios, ni conducirse conforme con los principios cooperativos, sino sólo beneficiarse de la fiscalidad cooperativa o no asumir los costes sociales y laborales de los trabajadores, podemos decir que es una falsa cooperativa y que la sanción prevista es la aplicación de la norma que se ha tratado de evitar. Además de ello, es posible que la falsa cooperativa sea descalificada como cooperativa y disuelta, salvo que la legislación permita su transformación en otra forma jurídica. A tal fin, las leyes cooperativas deberían recoger como causas de descalificación el incumplimiento de los fines y principios que son propios de las cooperativas y por tanto también las falsas cooperativas.

Si realmente hay voluntad política por erradicar las falsas cooperativas debería promoverse la información, formación y educación cooperativa de los socios, y la supervisión y control de las cooperativas, tanto interna como externamente. La tradicional obligación que tenían las cooperativas de atender a la educación de los socios en los valores y principios cooperativos, puede ser hoy sustituida por formación sobre el puesto de trabajo, difusión del cooperativismo, promoción de la inter-cooperación o del entorno (art. 56 LCE). Por otra parte, no hay en España un control, ni por parte de la Administración Pública ni por parte de las cooperativas, sobre si estas atienden preferentemente los intereses de sus socios, cumplen con su objeto social, o respetan los principios cooperativos, a diferencia de otros países de nuestro entorno ${ }^{52}$, y tal control contribuiría a conocer mejor las cooperativas, por parte de sus socios, trabajadores y entorno; a mejorar su funcionamiento y a prevenir falsas cooperativas. Se hace preciso instaurar mecanismos que aseguren ambas medidas, cuyo desarrollo podría ser encomendado a las asociaciones y federaciones de cooperativas siempre que contaran con los fondos necesarios para ello, los cuales deberían ser aportados por las propias cooperativas y por la administración pública. Mientras no conozcan los cooperativistas cuáles son sus derechos y obligaciones, cómo pueden y deben ejercerlos, y cuenten con instrumentos de control de la gestión de su cooperativa, siempre estarán expuestos a ser víctimas de prácticas fraudulentas como las analizadas en este trabajo.

52 Como es el caso de Alemania, Francia o Portugal. Véase al respecto Munkner (2017, 97ss). 


\section{Bibliografía}

ALTÉS TÁRREGA, J. A. (2018), “Análisis legal de las cooperativas de facturación y las cooperativas de impulso empresarial", Trabajo en plataformas digitales: innovación, derecho y mercado/Adrián Todolí Signes (dir.), Macarena Hernández-Bejarano (dir.), ISBN 978-84-9177-005-3, págs. 387-410.

BAYLOS, A., "Según Antonio Baylos", http://baylos.blogspot.com/

CASCALES MORENO, F.J., "La sentencia del Tribunal Supremo de 18 de mayo de 2018, sobre las falsas cooperativas de transporte", Tráfico y seguridad vial, №. 230, 201.

CICOPA (2018), Strategic Paper. The Future of Work: Where do industrial and service cooperatives stand? http://www.cicopa.coop/wp-content/uploads/2018/03/TheFuture-of-Work.pdf.

COMISIÓN EUROPEA, Pilar Europeo de los Derechos Sociales. https://ec.europa.eu/commission/priorities/deeper-and-fairer-economic-andmonetary-union/european-pillar-social-rights_es

FAJARDO, G. (2019), "Las cooperativas de transporte, socios colaboradores y falsas cooperativas: Comentario de la Sentencia del Tribunal Supremo no 2263/2018, de 18 de mayo", Revista de Derecho Mercantil, no 313, p. 12

FAJARDO, G. y ALZOLA BERRIOZABALGOITIA, I., "Las cooperativas de emprendedores y su contribución al emprendimiento en economía social". Ciriec. Revista Jurídica no 33/2018 pp. 145-183.

GARCÍA JIMÉNEZ, M. (2015), "El marco jurídico aplicable a los socios trabajadores de las cooperativas de trabajo asociado en España. Problemática y propuesta para su mejora", Empresas gestionadas por sus trabajadores: problemática jurídica y social/coord. por Gemma Fajardo García, págs. 187-192.

GARCIA JIMÉNEZ, M. (2018), "Innovación en la creación de empleo desde la economía social. Necesidad de su traslado a la legislación cooperativa y laboral para garantizar los derechos y la protección social de los socios trabajadores", en La promoción del emprendimiento y la inserción social desde la economía social (Coord: G. Fajardo), Valencia, Ciriec-España, pp. 79-86.

GARCIA JIMÉNEZ, M., "Falsas cooperativas, usos abusivos y derechos de los trabajadores. Análisis jurisprudencial y propuestas de actuación". Ciriec. Revista Jurídica de la Economía Social no 33/2018, pp. 185-222.

GRAU, C., "La modificació de la Llei: un retrocés per a les cooperatives". Revista Cooperació Catalana, 409 de maig 2017. Disponible en: http://www.rocagales.cat/nota-critica-a-lesmena-parlamentaria-que-modifica-laIlei-de-cooperatives-2/ 
HERNÁNDEZ-BEJARANO, M. (2017), "Nuevos modelos de cooperativas de trabajadores autónomos un análisis de las cooperativas de impulso empresarial y las cooperativas de facturación", Economía colaborativa y trabajo en plataforma: realidades y desafíos /Miguel Rodríguez-Piñero Royo (dir.), Macarena HernándezBejarano (dir.), págs. 145-185.

LÓPEZ GANDÍA, J. (2017), Cooperativas y Seguridad Social, Ed. Bomarzo, Albacete.

PAZ CANALEJO, N. (1994), Ley General de Cooperativas. Vol 3ㅇ Artículos 67 al final. EDERSA.

PERALTA DE LA CÁMARA, J.L. (2016), "Sobre la regulación del trabajo de los socios trabajadores en las cooperativas de trabajo asociado", La política y el derecho del empleo en la nueva sociedad del trabajo: Liber amicorum en honor de la profesora Rosa Quesada Segura / José Luis Monereo Pérez(dir.), Antonio Márquez Prieto (dir.), págs. 209-218.

TODOLI, A. (2018), "La jurisprudencia del Tribunal Supremo en materia de falsas cooperativas" en La promoción del emprendimiento y la inserción social desde la economía social (Coord: G. Fajardo), Valencia, Ciriec-España, pp. 87-90. 
This yearly series of working papers (WP) aims to publish works resulting from the scientific network of CIRIEC. The WPs are subject to a review process and are published under the responsibility of the President of the International Scientific Council, the president of the scientific Commissions or the working groups coordinators and of the editor of CIRIEC's international scientific journal, the Annals of Public and Cooperative Economics.

These contributions may be published afterwards in a scientific journal or book.

The contents of the working papers do not involve CIRIEC's responsibility but solely the author(s') one.

The submissions are to be sent to CIRIEC (iriec@uliege.be).

Cette collection annuelle de Working Papers (WP) est destinée à accueillir des travaux issus du réseau scientifique du CIRIEC. Les WP font l'objet d'une procédure d'évaluation et sont publiés sous la responsabilité du président du Conseil scientifique international, des présidents des Commissions scientifiques ou des coordinateurs des groupes de travail et du rédacteur de la revue scientifique internationale du CIRIEC, les Annales de l'économie publique, sociale et coopérative.

Ces contributions peuvent faire l'objet d'une publication scientifique ultérieure.

Le contenu des WP n'engage en rien la responsabilité du CIRIEC mais uniquement celle du ou des auteurs.

Les soumissions sont à envoyer au CIRIEC (ciriec@uliege.be).

This working paper is indexed and available in RePEc

Ce working paper est indexé et disponible dans RePEc

ISSN 2070-8289

ISBN 978-2-931051-29-0

EAN 9782931051290

http://doi.org/10.25518/ciriec.wp201930

D/2019/1406/30-d 


\section{WP Collection 2019}

2019/01 Évolutions récentes de l'économie sociale dans l'Union européenne Rafael CHAVES \& José Luis MONZÓN

2019/02 Recent Evolutions of the Social Economy in the European Union Rafael CHAVES \& José Luis MONZÓN

2019/03 Evolución reciente de la economía social en la Unión Europea Rafael CHAVES \& José Luis MONZÓN

2019/04 Die jüngsten Entwicklungen der Sozialwirtschaft in der Europäischen Union Rafael CHAVES \& José Luis MONZÓN

2019/05 Recente ontwikkelingen in de sociale economie in de Europese Unie Rafael CHAVES \& José Luis MONZÓN

2019/06 Italian cooperatives: an analysis of their economic performances, employment characteristics and innovation processes based on combined used of official data Carlo BORZAGA, Manlio CALZARONI, Chiara CARINI, Massimo LORI

2019/07 Rôle de l'Innovation Sociale dans le Développement Socioéconomique au Maroc : Premières Constatations à partir de la Littérature, et Etude de Cas de 4 Associations Socialement Innovantes Abdellatif BOUAZZA \& Youssef NAFIL

2019/08 De l'intérêt de créer un nouveau concept : la lucrativité limitée Laetitia DRIGUEZ

2019/09 International City Network and Public-Private Cooperation for Urban WaterEnvironment Management: A Study of Japanese Public Water Services' Overseas Expansion Naoki FUJIWARA

2019/10 Partnering with Civil Society Organizations. The role of volunteers and not for profit organizations in the provision of welfare services Federica VIGANÒ \& Andrea SALUSTRI

2019/11 ICT and Ethical Finance: Fostering Social Innovation and Financial Inclusion Gian-Luca GASPARINI \& Aurora PROSPERO

2019/12 New Trends in the Social and Solidarity Economy Regarding Agriculture and Food: A Comparison between France and India Antoine PERRIN

2019/13 Workers BuyOut: why employee-owned enterprises are more resilient than corporate business in time of economic and financial crisis?

The case of Emilia-Romagna Region Andrea BASSI \& Alessandro FABBRI

2019/14 How Social Enterprises Contribute to Alternative Food Systems Anastasia COSTANTINI, Gianluca PASTORELLI \& Alessia SEBILLO

2019/15 Measuring the Impact of a Social Enterprise - Case Study CONCORDIA Bakery, Romania Irina-Sinziana OPINCARU \& Doina CRÂNGAȘU 
2019/16 Vers un nouveau paradigme ancré dans les pratiques d'économie solidaire :

le délibéralisme

Éric DACHEUX \& Daniel GOUJON

2019/17 Social enterprises role in Romanian welfare system

Mihaela LAMBRU \& Claudia PETRESCU

2019/18 Community financing in the German organic food sector: a key for sustainable food systems?

Gerlinde BEHRENDT, Sarah PETER, Simone STERLY \& Anna Maria HÄRING

2019/19 Self-Management Report in Brazil - Technical Concepts and Challenges Daniel Francisco NAGAO MENEZES

2019/20 Creación de un nuevo bien común para las cooperativas agrícolas: Big data, TIC e intercambio de datos

Cynthia GIAGNOCAVO \& Daniel HERNÁNDEZ CÁCERES

2019/21 Job Quality in Economy for the Common Good Firms in Austria and Germany Laia OLLÉ-ESPLUGA, Johanna MUCKENHUBER \& Markus HADLER

2019/22 Social Innovation - Scaling Social Impact: a Danish Case Study

Roger SPEAR \& Carman Ka Man CHAN

2019/23 Shared-Services Cooperatives: Strengthening Local Economies through

Collaboration

Christina CLAMP, Eklou AMENDAH \& Carol COREN

2019/24 Les bonnes pratiques en matière de politiques publiques relatives à l'économie sociale européenne, à la suite de la crise économique

Rafael CHAVES \& José Luis MONZÓN

2019/25 Best practices in public policies regarding the European Social Economy post the economic crisis

Rafael CHAVES \& José Luis MONZÓN

2019/26 Buenas prácticas en las políticas públicas relativas a la economía social europea tras la crisis económica

Rafael CHAVES \& José Luis MONZÓN

2019/27 Platform Cooperativism in Italy and in Europe

Francesca MARTINELLI, Samuele BOZZONI, Simone CAROLI, Francesca

TAMASCELLI \& Giuseppe GUERINI

2019/28 Overview of social economy development in Slovakia and its promoting as the employment solution for long-term unemployed and disabled ones Lenka PČOLINSKÁ

2019/29 La Red Eusumo: instrumento público al servicio los ODS en Galicia María BASTIDA \& Ana OLVEIRA

2019/30 Falsas cooperativas de trabajadores y medidas adoptadas por los poderes públicos en España para combatirlas Gemma FAJARDO GARCÍA 


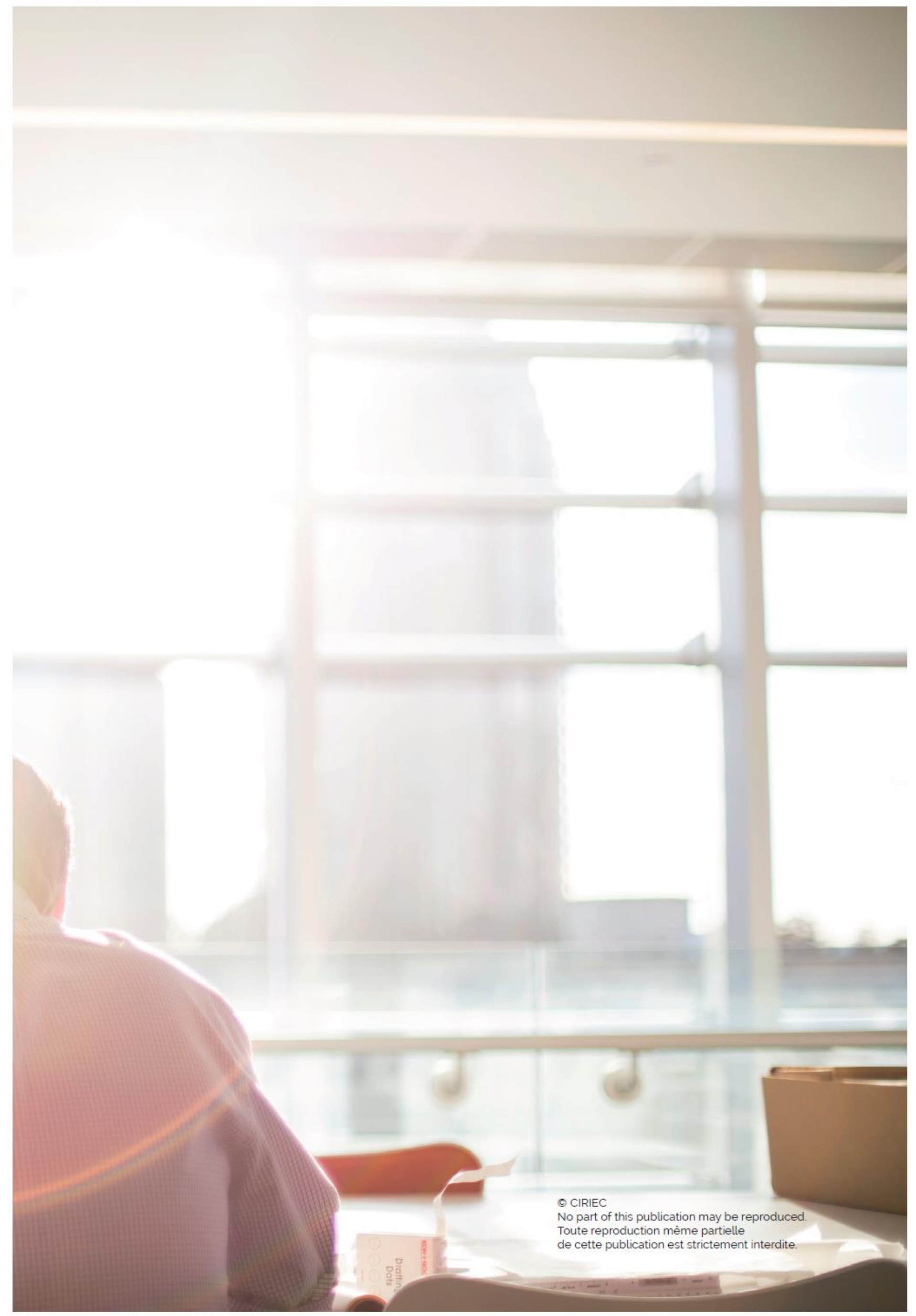


CIRIEC (International Centre of Research and Information on the Public, Social and Cooperative Economy) is a non-governmental international scientific organization.

Its objectives are to undertake and promote the collection of information, scientific research, and the publication of works on economic sectors and activities oriented towards the service of the general and collective interest: action by the State and the local and regional public authorities in economic fields (economic policy, regulation); public utilities; public and mixed enterprises at the national, regional and municipal levels; the so-called "social economy" (not-for-profit economy, cooperatives, mutuals, and non-profit organizations; etc.).

In these fields CIRIEC seeks to offer information and opportunities for mutual enrichment to practitioners and academics and for promoting international action. It develops activities of interest for both managers and researchers.

Le CIRIEC (Centre International de Recherches et d'Information sur l'Economie Publique, Sociale et Coopérative) est une organisation scientifique internationale non gouvernementale.

Ses objectifs sont d'assurer et de promouvoir la collecte d'informations, la recherche scientifique et la publication de travaux concernant les secteurs économiques et les activités orientés vers le service de l'intérêt général et collectif : l'action de l'Etat et des pouvoirs publics régionaux et locaux dans les domaines économiques (politique économique. régulation) : les services publics : les entreprises publiques et mixtes aux niveaux national, régional et local: « l'économie sociale » : coopératives, mutuelles et associations sans but lucratif : etc.

Le CIRIEC a pour but de mettre à la disposition des praticiens et des scientifiques des informations concernant ces différents domaines, de leur fournir des occasions d'enrichissement mutuel et de promouvoir une action et une réflexion internationales. Il développe des activités qui intéressent tant les gestionnaires que les chercheurs scientifiques.

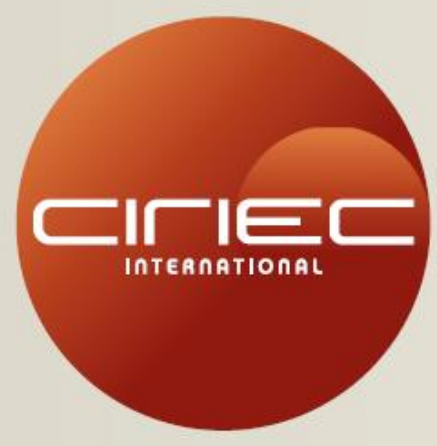

INTERNATIONAL CENTRE OF RESEARCH AND INFORMATION ON THE PUBLIC, SOCIAL AND COOPERATIVE ECONOMY-AISBL

CENTRE INTERNATIONAL DE RECHERCHES ET D'INFORMATION SUR L'ÉCONOMIE PUBLIQUE, SOCIALE ET COOPÉRATIVE - AISBL

Universite de Liège | Quartier Agora | Place des Orateurs 1 | Bātiment B33 boite 6 | BE-4000 Liege (Belgium) | T+32(0)436627 46 | F+32(0)43662958 ciriec@ulg.ac.be | www.cirieculg.ac.be 